BNL 50772

\title{
MUSTER
}

\section{ANNUAL HIGHLIGHTS OF THE NATIONAL CENTER FOR ANALYSIS OF ENERGY SYSTEMS}

\author{
Kenneth C. Hoffman
}

December 1977

Prepared for the

UNITED STATES DEPARTMENT OF ENERGY

by the

NATIONAL CENTER FOR ANALYSIS OF ENERGY SYSTEMS

BROOKHAVEN NATIONAL LABORATORY

ASSOCIATED UNIVERSITIES, INC. UNDER CONTRACT NO. EY-76-C-02-0016 WITH THE

UNITED STATES DEPARTMENT OF ENERGY 


\section{DISCLAIMER}

This report was prepared as an account of work sponsored by an agency of the United States Government. Neither the United States Government nor any agency Thereof, nor any of their employees, makes any warranty, express or implied, or assumes any legal liability or responsibility for the accuracy, completeness, or usefulness of any information, apparatus, product, or process disclosed, or represents that its use would not infringe privately owned rights. Reference herein to any specific commercial product, process, or service by trade name, trademark, manufacturer, or otherwise does not necessarily constitute or imply its endorsement, recommendation, or favoring by the United States Government or any agency thereof. The views and opinions of authors expressed herein do not necessarily state or reflect those of the United States Government or any agency thereof. 


\section{DISCLAIMER}

Portions of this document may be illegible in electronic image products. Images are produced from the best available original document. 


\section{ANNUAL HIGHLIGHTS OF THE NATIONAL CENTER FOR ANALYSIS OF ENERGY SYSTEMS $=$ $\overline{2}$ \\ Kenneth C. Hoffman}

\section{- December 1977}

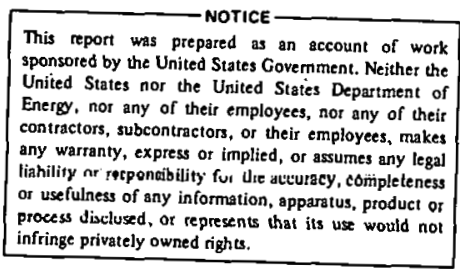

Prepared for the

UNITED STATES DEPARTMENT OF ENERGY

by the

NATIONAL CENTER FOR ANALYSIS OF ENERGY SYSTEMS

BROOKHAVEN NATIONAL LABORATORY UPTON, NEW YORK 119.73 


\section{NOTICE}

This report was prepared as an account of work sponsored by the United States Covernment. Neither the United States nor the United Stateo Department of Energy (DOE), nor any of their employees, nor any of their contractors, subcontractors, or their employees, makes any warranty; express or implied, ur assunies any leyal liabilicy or responsibility for the accuracy, completeness or usefulness of any information, apparatus, product or process disclosed, or represents that its use would not infringe privately owned rights.

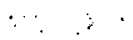

Printed in the United States of America Available from

National Technical Information Service

U.S. Department of Commerce 5285 Port Royal Road Springfield, VA 22161

Price: Printed Copy $\$ 6.50$; Microfiche $\$ 3.00$

February 1978

800 copies 


\section{ABSTRACT}

The National Center for Analysis of Energy Systems at Brookhaven has been in operation since January 1976. This annual highlights report outlines the scope of activities of the Center involving the integrated analyses of technological, economic, environmental, and social aspects of energy at the regional, national, and international levels. The objectives of the center and major accomplishments of 1977 are described along with a list of active projects and publications. The energy data bases and analytical models used in the course of policy analyses are also described.

The major ongoing activities of the center include:

- long-range forecasting of energy-economic relationships,

- regional energy and environmental policy,

- comparative health effects of alternative energy systems,

- technology assessment and energy R\&D priorities,

- development of energy-economic-environmental models and data bases,

- R\&D strategies for International Energy Agency, and

- energy technologies for developing countries. 
THIS PAGE

\section{WAS INTENTIONALLY \\ LEFT BLANK}


List of Tables $\ldots \ldots \ldots \ldots \ldots \ldots \ldots \ldots \ldots \ldots \ldots \ldots \ldots \ldots \ldots$

List of figures $\ldots \ldots \ldots \ldots \ldots \ldots \ldots \ldots \ldots \ldots \ldots \ldots \ldots$

Introduntion $\ldots \ldots \ldots \ldots \ldots \ldots \ldots \ldots \ldots \ldots \ldots \ldots \ldots \ldots \ldots \ldots \ldots$

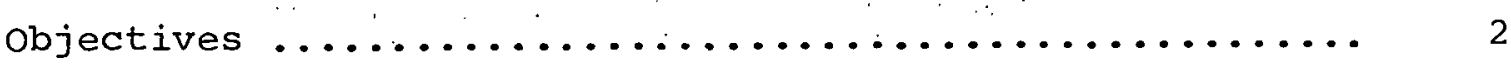

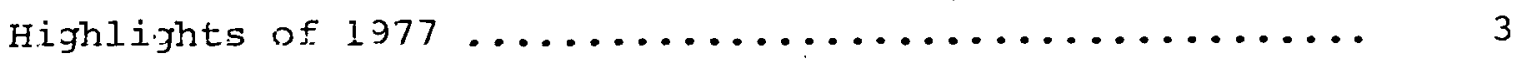

Major Activities Planned for $1978 \ldots \ldots \ldots \ldots \ldots \ldots \ldots \ldots \ldots$

organization $\ldots \ldots \ldots \ldots \ldots \ldots \ldots \ldots \ldots \ldots \ldots \ldots \ldots \ldots \ldots$

Relationship to other Activities ................ 27

scope of Activities : ........................ 29

1. Policy Analysis ....................... 29

2. Exonomic Analysis .................. 30

3. Biomedical and Environmental Assessment ....... 31

4. Technology Assessment ................. 32

5. Energy Data and Models ................. 33

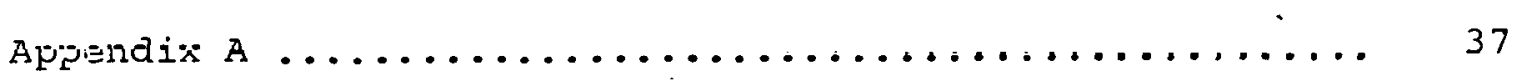

Appendix в $\ldots \ldots \ldots \ldots \ldots \ldots \ldots \ldots \ldots \ldots \ldots \ldots \ldots \ldots \ldots \ldots$

Appendix $c \ldots \ldots \ldots \ldots \ldots \ldots \ldots \ldots \ldots \ldots \ldots \ldots \ldots \ldots \ldots . \ldots \ldots \ldots$ 


\section{LIST OF FIGURES}

Figure No.

Title

Page

1

2

3

4

5

6

7

8

9

$\mathrm{B}-1$

B-2

Table No.

I
Comparison of Coal-Fired and Nuclear Power Costs Under Existing and Proposed Environ-

mental Regulations

Sectoral Energy Differentials, Japan-United States

BECOM: Structure of Residential Space Heat

Schematic Representation of Regional Energy Facility Siting Analysis

The Combined Effects of Income and Pollution by Age on Total Mortality

Population Exposure Density, Arbitrary scale

Oil Imports, $10^{15}$ Btu, 2000

Environmental Index, 2000

Organization Chart--National

Center for Analysis of Energy

Systems

28

Polioy Considerations

65

Reference Energy System

65

\section{LIST OF TABLES}

Title

Page

Effects of Pricing Policies on Encrgy Uemand and GNP, Year 2000 
INTRODUCTION

The National Center for Analysis of Energy Systems (NCAES) was established at Brookhaven in January 1976. The formation of this Center gave recognition both to the need for detailed interdisciplinary studies of the relations between the technological, economic, social, and environmental factors of energy systems and to the previous work done by the Brookhaven groups in these areas of energy systems analysis. The staff includes expertise in the areas of science, technology, economics, planning, health and safety, information systems, and quantitative analysis. In order to relate the technological aspects of energy to other policy areas including economics and the environment, work is performed when appropriate for other federal agencies and for state and regional agencies, regulatory bodies, and planning groups.

The emphasis of the programs at the center is on planning studies at the regional, national, and international level in areas of special import to energy $R \& D$ policy formulation. This work is designed to assist the Department of Energy (DOE) in the formulation of energy policies that are responsive to the nation's needs. A portion of the program effort is devoted to the development of planning frameworks, analytical models, and data bases that are required to give adequate support to the planning studies. Thus the program involves both operational support to DOE and original research in energy systems analysis. Individuals associated with the Center have engaged in a number of major panel and committee activities in the energy area. The research component of previous programs on which the Center is based has led to the development of analytical methods and data bases that are widely used at the federal level as well as by industry and universities. These unique 
analytical techniques emphasize technological detail and are employed in support of the planning studies.

\section{OBJECTIVES}

Special objectives of the National Center for Analysis of En^rgy systems are:

1. To perform energy technology assessments on a continuous basis to support DOE planning and budget allocation.

2. Tu develop long-range energy-economic projections.

3. To analyze biomedical and environmental impacts of energy strategies.

4. To perform special regional and national policy studies.

5. To explore international aspects of energy in relation to technology and policy.

6. To develop improved data bases and analytical methods for, use in energy policy analysis and technology assessment.

7. To provide a central focal point for the coordination and integration of energy data and models through collaborative efforts with universities and industry.

8. To maintain current information on the technical, economic, and environmental characteristics of energy technologies for use by DOE and other agencies engaged in energy technology assessment.

9. To cooperate with and assist other federal agencies, regional planning and regulatory agencies, universities, and industry groups in the analysis of special problems of mutual interest and in the dissemination of information and analytical methods.

10. To provide a site and support facilities for workshops and special task groups assembled to address important topics. 


\section{Energy Technology Assessments and Projections}

- Completed a study of potential coal use in the year 2000

- Completed a study comparing energy use in Japan with that in the United States

- Began a study of the impacts of decentralized energy technologies on future united states energy use and lifestyles

- Completed an analysis of selected conservation options which include potential economic and energy savings

- Supported DOE in the development of long-range energy forecasts and in the analysis of the long-term impacts of the National Energy Plan

- The analysis of the national energy policies utilized the Brookhaven Energy System Optimization Model to assess the impact of proposed taxes on oil and gas, particularly in the industrial and utility sectors, upon fuel use patterns in the energy system. This analysis was carried out to the year 2000, and indicated the magnitude of the shifts to coal from oil and gas that might occur and the technology to be employed. Higher fuel costs provide an incentive for solar options under this plan.

The study of coal use analyzed future supply and demand relationships on a regional basis, taking into account the transportation complexities and sulfur content of coal from various supply regions. The study assessed future siting and economics of synthetic fuels from coal. In addition, it also indicated that the implementation of stringent enission standards based on Best Available control Technology amendments to the Clean Air Act could dampen the development of Western coal resources and enhance the cost 
competitiveness of nuclear power, compared to a case under present New Source Performance standards. The cost comparisons in various regions are summarized in Figure 1 .

Comparisons of energy use among nations is useful for estimating improvements in energy options based upon the experience of others. A previous study comparing energy use in Sweden with that in the U.S. was very instructive and a new study comparing the U.S. with Japan indicates the lower per capita consumption by the Japanese is mainly due, in the residential and commercial sectors, to lifestyle and cultural differences, rather than technological distinctions. The industrial sector of Japan is distinctively more efficient because of the more recent vintage of its capital stock. The transportation sector in Japan uses mass transit to a much greater extent than in the U.S. In summary, personal consumption of energy in Japan is inextricably linked to income levels and cultural factors. Figure 2 compares sectoral energy differentials between the two nations.

\section{Economir and Conservation Analyeis}

- Application of coupled Brookhaven and Hudson-Jorgenson model to. long-term energy-economic projections under alternative energy pricing policies

- Completion of analysis of energy conservation policy as a means of ameleorating the oil supply crises foreseen by some in the $1980^{\prime} \mathrm{s}$

Fnergy-Economic Analysis

During FY 1977 primary emphasis was devoted to analyzing the potential ranges of economic and environmental impacts of alternative energy policies through the application of the various BNL and DRI energy, economic and environmental models. Evaluations of 

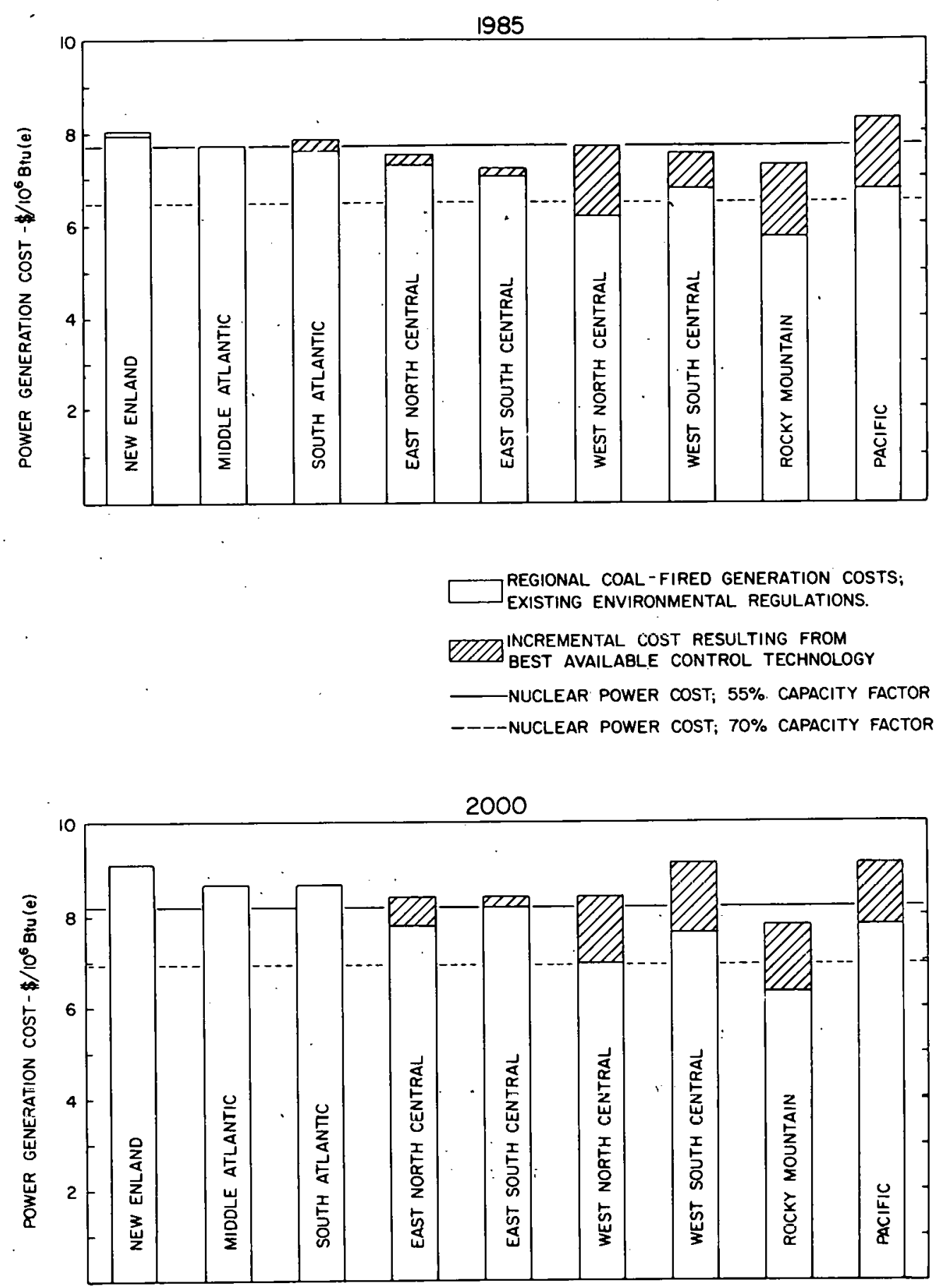

Figure 1. Comparison of coal-fired and nuclear power costs under exioting and proposen environmental regulativis. 

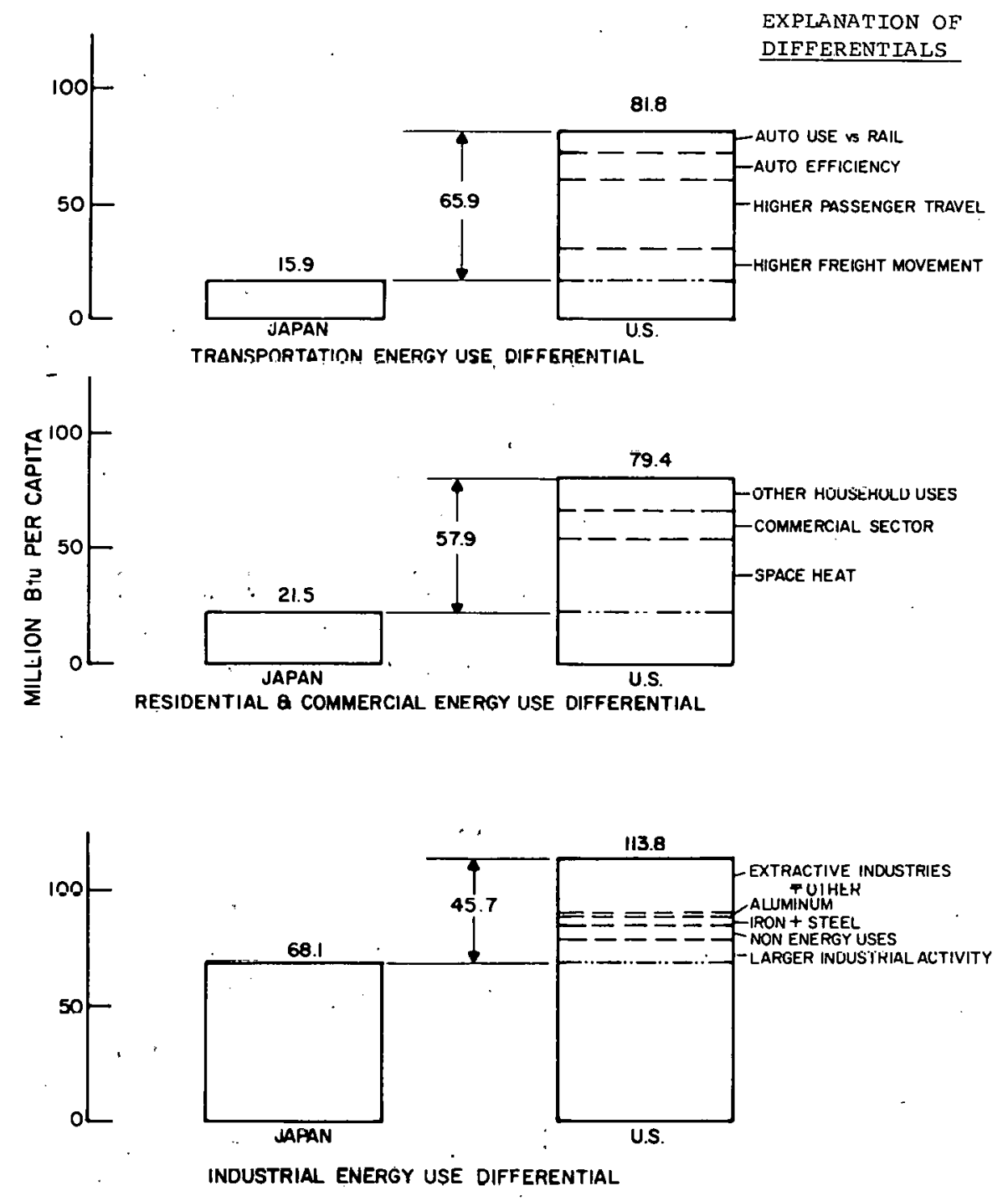

Figure 2. Sectoral energy differentials,
Japan-Unitcd Etates. 
several potential future energy policies, including nuclear moratorium legislation and conservation-oriented energy taxes and subsidies were performed. Several improvements were also made in the models currently being used for energy policy analysis. These include the development. of detailed linking equations for integrating two Brookhaven models (BESOM and IO) and the Hudson-Jorgenson (H-J) model. In addition, the dynamic version of BESOM was linked to the Hudson-Jorgenson model. The major results of a policy study involving the use of energy taxes to reduce demand and estimation of the import on GNP are shown in Table $I$.

Transportation Conservation

The Division of Transportation Energy Conservation requested that NCAES develop a framework for estimating the amount of energy. used to transport energy materials under alternative energy scenarios. In response to this request. NCAES developed the Brookhaven Energy Transportation Submodel (BETS). BETS uses BESOM solution values, user assumptions, and other transportation parameters, to produce energy consumption values attributed to the movement of specific energy materials on śpecific transportation modes.

Buildings and Community System (BCS) Conservation Options

One of the most important opportunities for conservation lies in our buildings and the energy conversion system which support them. The BCS program in NCAES is directed toward the application of existing tools to the program evaluation needs of BCS; the development of new tools where appropriate; the support of BCS and BCS contractors by providing background on prices, growth, and other considerations; and participation in the Residential/Commercial working Group of the ERDA Market oriented Program Planning study (MOPPS). 
TABLE I

Effects of Pricing Policies

on Energy Demand and GNP, Year 2000

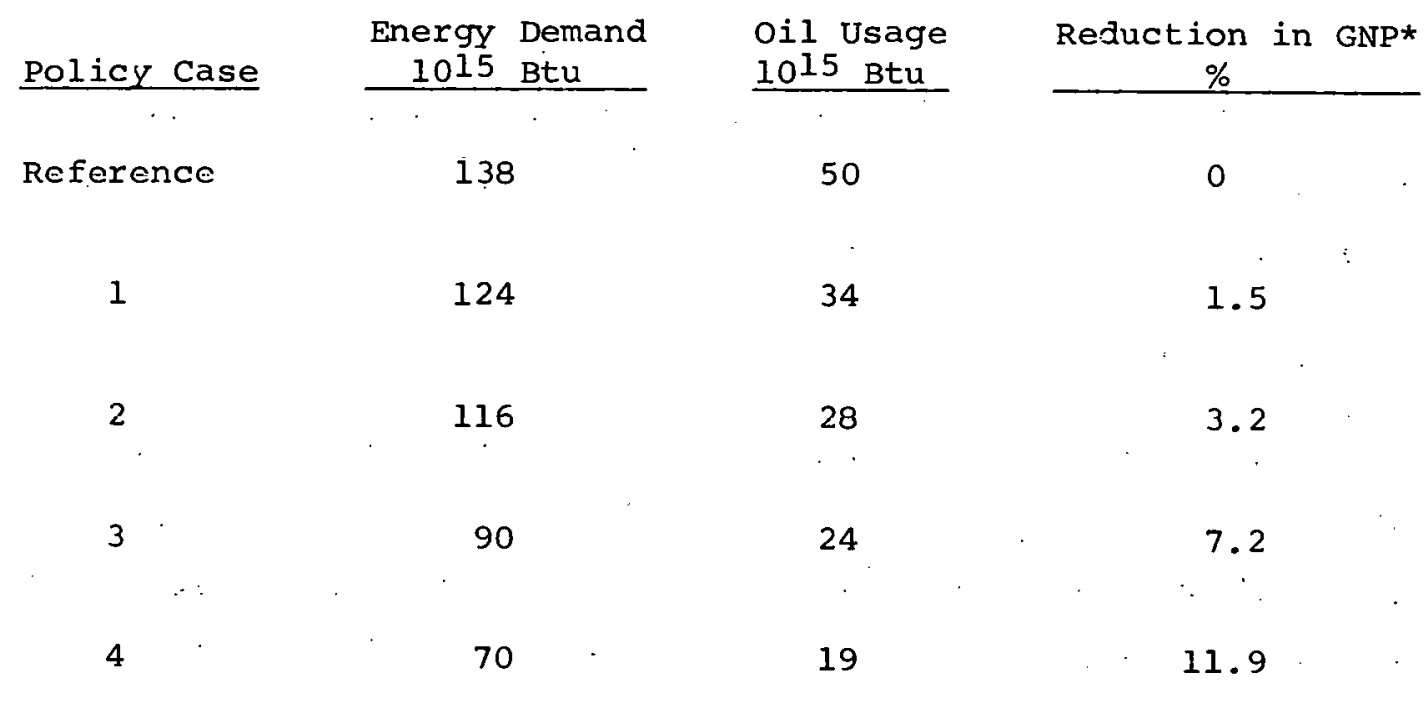

${ }^{\star}$ From reference year 2000 level $\$ 2791 \times 10^{9}$. 
The end use conservation model, BECOM, assesses both new and retrofit conservation technologies in nine building types and four regions in a linear programming framework. The network description of BECOM developed as an extension of the Reference Energy System is shown in Figure 3.

\section{Industrial Conservation}

The industrial energy conservation effort concentrated its efforts on assessing the system-wide impacts of energy conservation technologies within several industries through the use of linear programing cost optimization models for each industry: The industries covered included cement, iron and steel.. aluminum, and paper and pulp. The effect of energy prices, policy options, and investment cost on the rate of market penetration of new technologies was assessed. The sensitivity of market penetration to capital cost and energy prices, and the synergism between competing technologies provide crucial data on which R\&D funding decisions can be based. For the paper and aluminum industries some regional effects can be analyzed due to the limited regional disaggregation of these models.

Conservation Policy

The Economic Analysis Division conducted an overview assessment of the role of energy conservation and solar application in the context of global energy supplies and economic growth: This study was sponsored by the office of Conservation Planning and Policy and conducted in collaboration with energy economists at Cornell University. Special attention was directed to the role of the global oil market on U.S. energy supplies; the interaction of energy supplies and prices with the economy as a whole; the clarification of the specific role of the federal. government together 


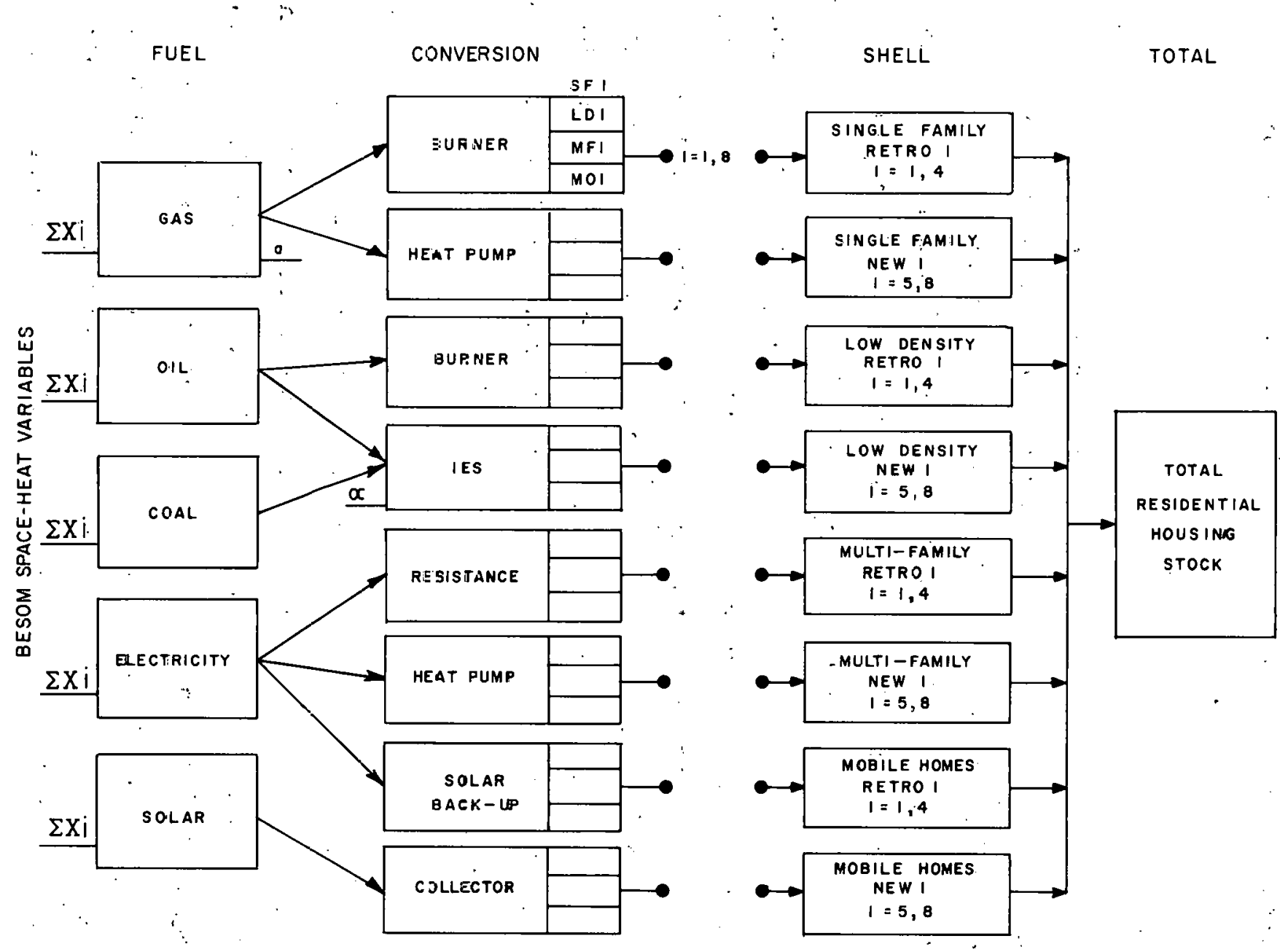

Figure 3. BECOM: Structure of residential space heat. 
with business and other institutions in promoting energy conservation and solar applications; and the development of improved approaches to managing federal programs in these areas.

Support of External Modeling Activities

The dynamic energy system model developed at Brookhaven, DESOM, was one of six models applied to energy analysis by the Modeling Resource Group of the National Academy of Sciences Committee on Nuclear and Alternative Energy Systems (CONAES). The focus of the CONAES study was on energy needs for 2010. The models were used to project the electric and nonelectric energy consumption and technologies employed under different policy scenarios. In addition to participating in the CONAES study, the ECOnomic Analysis Program also supported the Energy Modeling Forum. The Energy Modeling Forum seeks to improve the usefulness of formal models as aides for decision-making by clarifying and communicating the capabilities of existing models. The Forum examined six models, one of which was the combined Brookhaven and HudsonJorgenson model. The implementation of this linked system is achieved through information transfers for three tärget years of 1985, 1990, and 2000 between the Hudson-Jorgenson (DRI) Model and the combined Input-Output-BESOM. The DRI model is used on an intertemporal integrating device with the static I/O-BESOM model providing energy technology detail for the three target years.

\section{International Programs}

- Completion of first phase of IEA Energy Systems Analysis project

- Contributed to the analytical section of the plan for the U.S. Technical Energy Program for Developing Countries 
Collaboration with Directorate for Science, Research, and Education of the Commission of European Communities on energy-economic data and model development

\section{IEA Energy Systems Analysis}

A brief summary of the results obtained during the initial ten months of the International Energy Agency Energy Systems Analysis Project was prepared jointly by BNL and Kernforschungsanlage, Julich (with scparatc national data appondioos for each of the 13 participating countries and a separate "Resource Evaluation" appendix). During the second phase of the project (April 1, 1977 through March 31. 1979) preliminary analytical results for many IEA scenario cases will be completed in late April 1978; however, most reports in FY 1978 will be informal in nature and only for internal use of the national delegations to the IEA.

The March 25, 1977 report describes the historical energy flows for calendar year 1974 for each of the 13 participating countries (Belgium, Canada, Denmark, the Federal Republic of Germany, Ireland, Japan, the Netherlands, Norway, Spain, Sweden, Switzerland, the United Kingdom, and the United States). Reference projections of the energy systems were prepared for the years 1985 and 2000 , and the possible role of 18 new technologies were evaluated in a preliminary way. The data were prepared jointly by two teams working at BNL and KFA composed of one or more representatives from each of the participating countries. The results underscore the urgency for collective action by the-industrial nations of the world in finding substitutes for petroleum during the next two decades. 


\section{Regional Energy Studies}

- Assessment of the solid waste management impacts of the Administration's proposed National Energy Plan

- Assessment of the Impacts of the Administration's proposed National Energy Plan on the Northeastern United States

- Completion of a major study of the Air Quality and Health Impacts of increased coal utilization, prepared at the request of the National Academy of Sciences Committee on Nuclear and Alternative Energy Systems

- Development of an electric facility siting model for disaggregation of regional energy system scenarios to the county level

- Assessment of New Jersey's 1976-1977 Natural Gas Supply Crisis

- Establishment of a state Advisory Committee, with a representative from each state designated by the Governors of the Northeast

- Participation in the National Coal Utilization Assessment, a multi-laboratory effort sponsored by ERDA-DOE's Integrated Assessment Program

- Preliminary feasibility analysis of offshore coal fired electric generating plants

- Detailed assessments of the current and future potential for industrial coal utilization in the Northeast

- Prepared preliminary energy Research, Development, and Demonstration Plan for the state of New York (in collaboration with Donovan, Hamester, and Rattien, Inc., and the State University of New York at stony Brook)

Health Impacts of Sulfates from Fossil Fuel Combustion

In a major effort in support of the National Academy of Sciences' Committee on Nuclear and Alternative Energy Systems (CONAES), the Brookhaven Long Range Diffusion-Trajectory Model was applied to cmissions from existing and anticipated electric utility plants. Using the Lave-Seskin dose response function to quantify health 
impacts, it was found that a significant probability existed that excess mortality levels from fossil fuel combustion might reach 20,000 deaths per year.

Solid. Waste Impacts of the National Energy Plan

In an assessment of the impact of the National Energy Plan (NEP) on solid waste generation in the electric utility and industrial sectors, it was determined that the NEP, by 1985, would result in slightly lower quantities of ash and scrubber sludge disposal in the electric utilities, but considerably higher disposal requirements in the industrial sector. Problems in industry wcre found to influence the choice of FGD systems utilized, and a significant proportion of industry would elect to use liquid scrubbing systems, with a discharge to municipal sewers and receiving waters, rather than become entángled in lócăl sölid wăste manăgement controversy. This study was prepared at the request of the Executive office of the President.

Energy Facility siting

As part of the Natinnal sonal Utilization Assessment, extensive siting analysis was conducted for the Northeastern United States. Major findings include the presence of severe water resource constraints in the Middle Atlantic states, leading to the requirement for dry cooled nuclear and coal technologies, and off-shore siting; the existence of severe land use constraints on the New England Coast, severely limiting the ability to attain postulated levels of electric demand bcyond 2020, and the rcquircment for nuclear energy centers in upstate New York beyond 2010. The nonsignificant deterioration provisions of the Clean Air Act Amendment were found to constrain coal siting in upstate New York and northern Maine. 
The methodology used in this siting analysis is shown in Figure 4 and is now the subject of a special assessment to be conducted for the Massachusetts Energy Facilities Siting Council for analysis of regional siting problems in New England.

Environmental studies and Biomedical Assessment

- Collaboration in the preparation of the Environmental Development Plan for the USERDA Conservation Research and Technology Program.

- Scenario analysis for the U.S. Water Resources Council in support of the National water Assessment

- Analysis of various oil spill and pollution episodes in the Northeast prepared for various public agencies using the BNL Ocean Transport Model

- Assessment of the Acid Rain Problem in the Northeast

- Comparison of population exposure to air pollution to supply heat demand from (a) high-Btu gas from coal, (b) coal to electric heat, and (c) wellhead natural gas

- Analysis of conflict between energy developments and endangered species distributions

- Analysis of the importance of individual exposure data in assessment health impacts of air pollution

- Survey of the health effects of insulation materials and development of mathematical models of indoor air pollution that take into account reduced energy consumption due to conservation measures, and changing outdoor air pollutant concentrations

- Sponsored workshop entitled "The Impact of water Availability on New England Energy and Economic Development"

- Reports on implications of New Source Performance Standards for emerging technologies with special emphasis on EPA's proposed New Source Performance Standards for Lurgi coal gasification plants

- A workshop and report on potential ambient air quality standards for atmospheric sulfates and preliminary analysis of the policy implications of these standards 


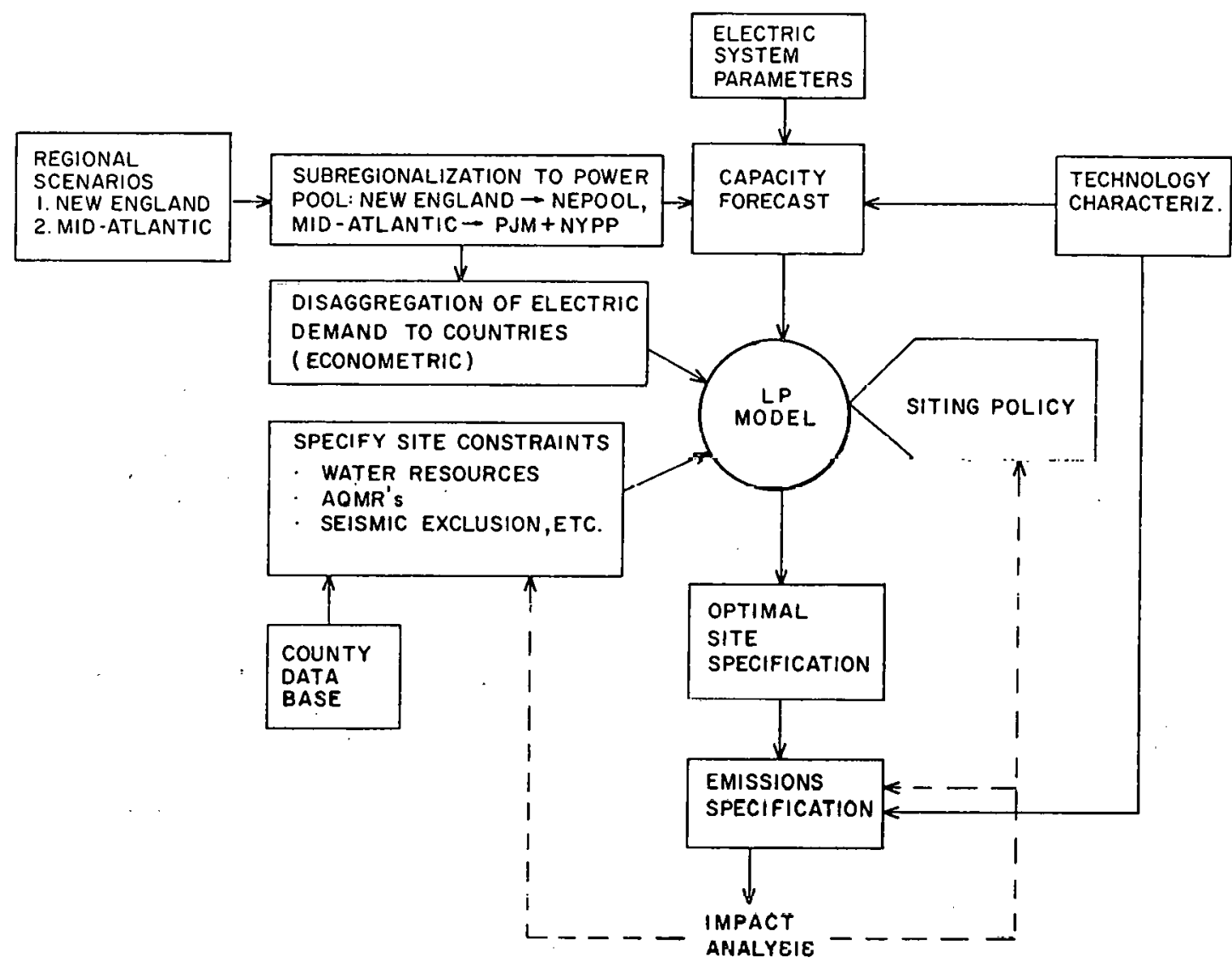

Figure 4. Schematic representation of regional energy faclitty siting analysis. 
- A workshop and report on innovative methods of quantifying environmental impacts of energy production and use

- Preliminary reports on potential health and environmental impacts of decentralized energy. systems, including solar energy systems.

\section{County Level Data Base}

The Data Bank is organized by facility type and the county in which the facility is to appear. The facility type is further classified according to fuel type, the supply activity to which the facility belongs, and the process type to be implemented. A numerical indexing scheme is assigned to all classification elements for purposes of retrieval, updating, and model interfacing.

Socineronomic Analysis

The relationship between air pollution, mortality, income, and several demographic variables was detected using the MEDABA file. Results are shown in Figure 5 . The pollution effect can be traced at two different levels: (1) a weak effort in increasing mortality at younger ages and (2) a nonspecific effect on increased cardiovascular disease, is highly income dependent (i.e., only evident in high income levels exposed to high pollution). On the other hand, an effect is not detectable in low income high pollution levels. The pollution effect on chronic discases can be traced to chronic ischemic heart disease. Because this specific cause of death shows a strong association with pollution levels in conjunction with its rising incidence as a major cause of death, the need for more extensive research in this area is clearly mandated. Our findings show an association of pollution with malignant meoplasms that is age dependent, and is nonsite specific. 
Measure of correlation of income and

pollution with mortality at each age:

(Indicates effect of pollution on increased

mortality in age group over 30 , and protection

afforded by income to reduced mortality in all

age groups).

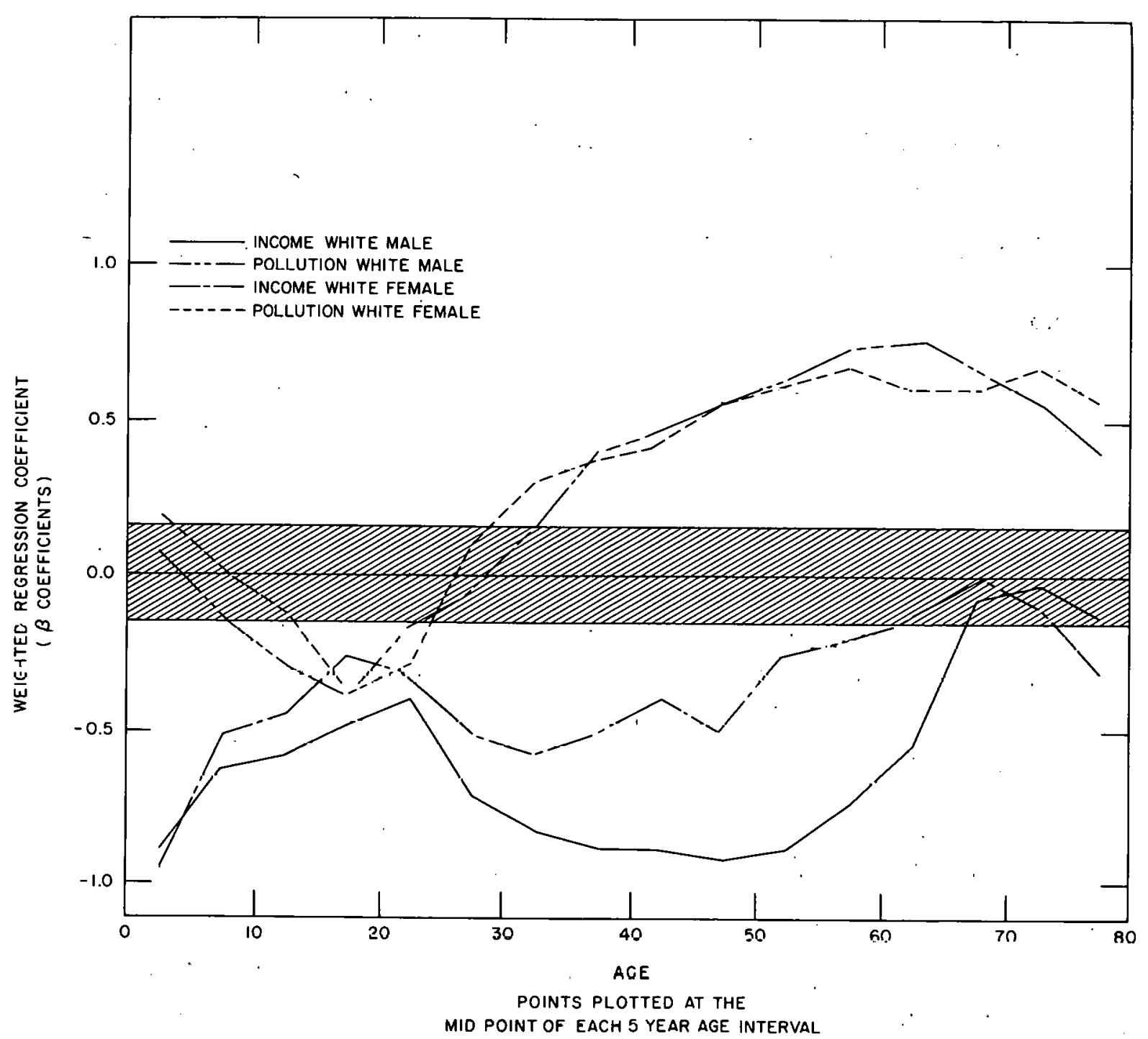

Figure 5. The combined effects of income and pollution by age on total mortality. 
Individual Exposure study

A simulation study was conducted to determine the distribution of individual exposures to $\mathrm{SO}_{2}$ within a population. Neither urban nor suburban fixed monitoring sites proved to be good estimates of the population exposure. This is illustrated in Figure 6. An assessment of the potential for individual air pollution monitors as a means of better defining population exposure was conducted.

Methods and Data

Methods have been developed for integrating health impacts with energy networks. The technique associates health impact coefficients with each process in the network. The method considers deaths, injuries, and illnesses. Uncertainty is accounted for by providing best estimate and upper and lower range of estimate. The impacts of each process are calculated and these can be aggregated to any level or by any criteria desired.

Environmental coefficients within the current Brookhaven energy data bank were reviewed and recommendations for incorporating existing data into a new Biomedical and Environmental Modeling Information System (BEMIS) were made.

An interface program was developed that recasts BESOM aggregated energy outputs and generates an ESNS output containing the full set of disaggregated process-level emissions for both supplies and end uses.

A county-level water quality file was created for New England and Mid-Atlantic states. Data includes numerous statistical values for over 50 parameters, ranging from toxic metals and nonmetals, radionuclides, organics, harness related variables, and pesticides.

The National Residuals Discharge Inventory was brought inhouse, with approximately $60 \%$ of its software converted to run on 
Simulated distribution of annual average exposure - level in the population of a highly polluted urban area compared with annual average concentration at urban and suburban fixed monitoring sites.

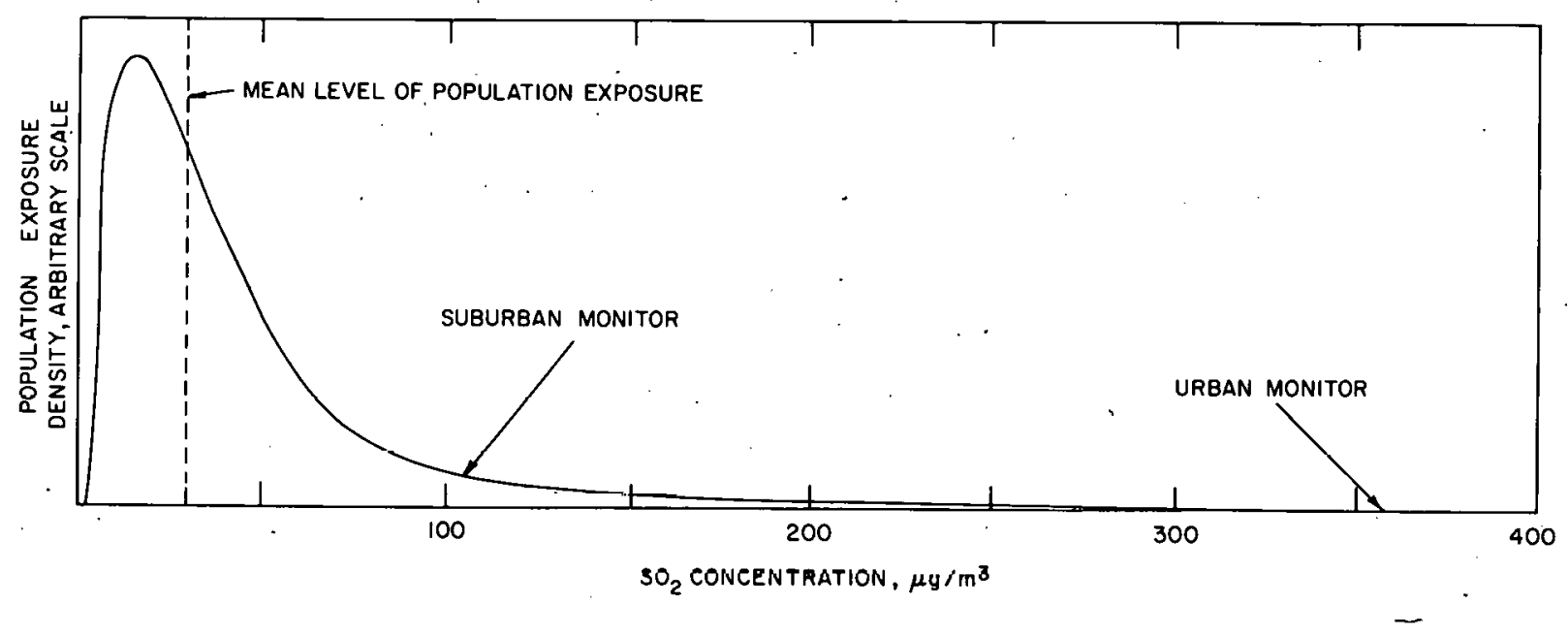

Fiqure 6. Population exposure density, arbitrary scale. 
our. CDC computer and much of its relevant data extracted for BEAD analyses.

\section{Energy Data and Model Development}

- Development of a multi-region version of the Brookhaven Energy System optimization Model

- Implementation of time-step optimization model for analysis of time dynamics of energy systems

- Multi-objective analysis of energy futures

The Multị-Regional Energy Model

The Multi-Regional Energy System Optimization Model (RESOM) was developed and applied to policy analysis. The energy sector is represented in this multi-regional model, which optimally allocates regionally produced energy resources and selects the optimal regional mix of energy supply, conversion, and end use technologies according to some objective criteria which may include cost, efficiency, and environmental impacts. Regions are linked by interregional energy flows and transportation networks. Work was initiated on linking the energy sector model with a multi-regional interindustry model of the economic system, where the regions are also linked by interregional industrial flows. The Multi-Regional Model may be used in a time-dynamic version by employing the timestep technique developed for BESOM.

Time-Stepped Version of BESOM (TESOM)

The Time-Stepped Energy System Optimization Model was conceived and developed to provide an improved, automated, simulation capability and an alternative decision-making tool to assist in the study of the evolution of national energy supply/demand distribution 
systems...TESOM can be classified as a "myopic" time-phased model in that the optimal levels of the decision variables for any timestep are determined entirely from the optimal levels of the decision variables in the previous time-steps, and the assumptions on the retirement/deterioration rates and average lifetimes of "old" stock, with associated sosts, and the "current" assumptions involving energy-related economic and technological factors, potentially including both short-term and long-term supply curves. Since TESOM is "myopic" it can be used to evaluate the effect of "surprises or shocks" to the energy system that are not foreseen until some later date.

Sample results of mule1-objective trale-off allalyses ase sliuws in Figures 7 and 8 .

NEDS/REPS Environmental Model

The National Emission Data Service (NEDS) and Regional Emission Projection System (REPS) models developed by Booz Allen were made operational on the BNL computer system. Two basic studies were performed using NEDS/REPS which entailed many modifications to the model aystam. 


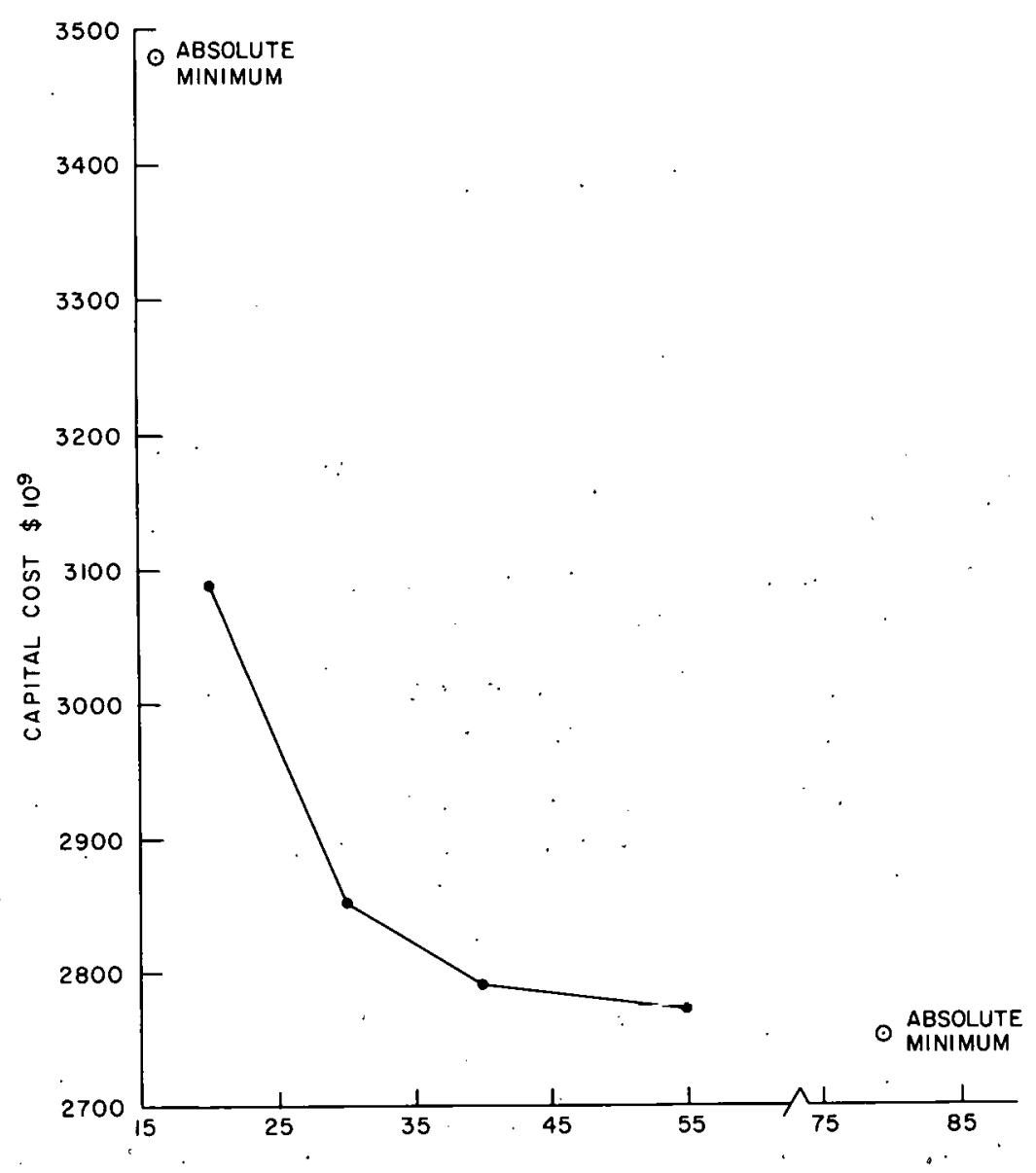

Figure 7. Oil imports, $10^{15} \mathrm{Btu}, 2000$.

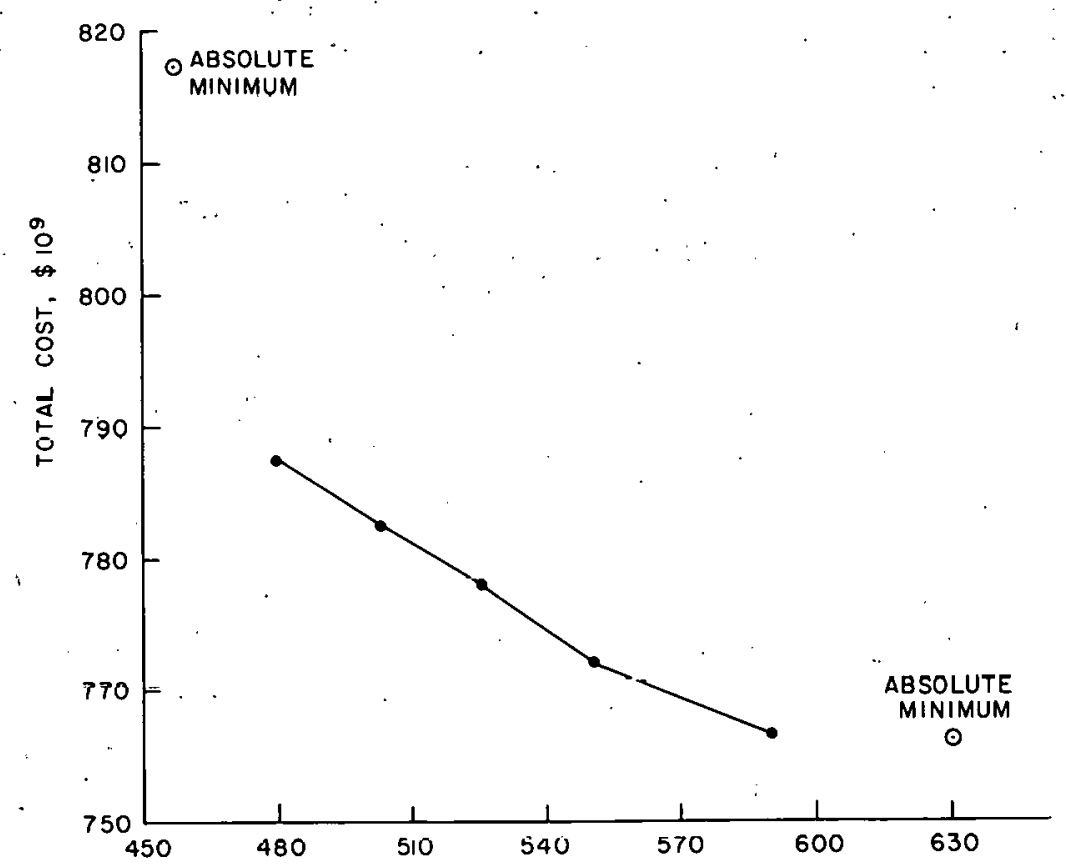

Figure 8. Environmental index, 2000. 
Technology Assessment

- Completion of study of decentralized systems and impacts on U.S. energy use

- Development of a new set of energy use baselines, and updating of the Sourcebook for Energy Assessment

- Completiun ur a study of multi-objective analyoio tcchniques applied to energy strategies

- Completion of a study of solar-storage-backup trade-offs for decentralized electric supply to small community systems

\section{Economic and Conservation Analysis}

- The development of multi-regional energy-economic models

- Continue efforts to more fully integrate the multiregional energy model with the national energy-economic models from above and the sub-regional energy-environmental models from below

- The Conservation Policy and Planning program will place special emphasis on understanding the relationship between ever tightening world oil markets and the U.S. conservation program

- The Buildings and Community Systems Conservation program will move intensively into analysis of price, incentive, standards and other areas of DOE responsibility, while maintaining the RD\&D analysis capability developed in FY 1977

- The industrial energy conservation project intends to extend the availability of process models, including conservation options, to include the cement, glass, food, and textiles industries. This work will be done through collaborative arrangements where possible. 
- Develop a hierarchical framework for incorporating various existing models into a system specifically designed for integrated energy/environmental/economic policy analysis

\section{Regional Programs}

- Assessment of the utilization of refuse derived fuel for the state of Maryland

- Analysis of regional energy facility siting strategies for New England, conducted in conjunction with the Massachusetts Energy Facilities siting Council

- Initiation of a detailed assessment of the regional economic impact and regional development consequences of conservation strategies in the Northeast

- Completion of the National Coal Utilization Assessment, culminating in a series of symposia on coal utilization and its impacts in the Northeast

- Assessment of the relationships between energy development, water resource constraint and economic development in New England

International Programs

- Completion of energy $R \& D$ assessment in support of $R \& D$ strategy development for the International Energy Agency

- Completion of assessments of four developing countries in support of the U.S. Technical Energy Program for IDC

- Preparation of a study for the Agency for International Development on the energy future of developing countries and priority areas for U.S. assistance programs

\section{Environmental Studies and Assessments}

- Continue analysis of transport, conversion, and health effects of sulfates

- Analyze environmental characteristics and impacts of decentralized energy systems 


\section{Energy Data and Models Development}

- Application of the regional and time-stepped models to technology assessment

- Application of the NEDS/REPS system to environmental policy analysis 
The Center is organized within the Department of Energy and Environment as shown on the attached organization chart (Figure 9). The Biomedical and Environmental Assessment Division, a joint program between the Medical Department and the Department of Energy and Environment, is affiliated with the center. Working groups have been assembled in several areas with specific program responsibilities. These areas are:

1. Policy Analysis

2. Economic Analysis

3. Biomedical and Environmental Assessment

4. Technology Assessment

5. Energy Data and Models

Each of these working groups draws on the collective skills and capabilities of the staff including chemical, electrical and mechanical engineers, physicists, chemists, physicians, ecologists, epidemiologists, economists, applied mathematicians, and computer specialists. The staff has long-term experience in energy research and development. Many consultants from.industry and the academic community are engaged on a continuing basis and contribute to the program as the need arises.

\section{RELATIONSHIP TO OTHER ACTIVITIES}

The programs now included in the Center have provided analysis and support for DOE, the National Science Foundation office of Energy R\&D Policy, the office of Science and Technology, and the Council. on Environmental Quality. Collaborative work is in progress with other agencies, federal and state.

Personnel from the Center have participated in special energy panels and studies sponsored by the National Academy of sciences, 


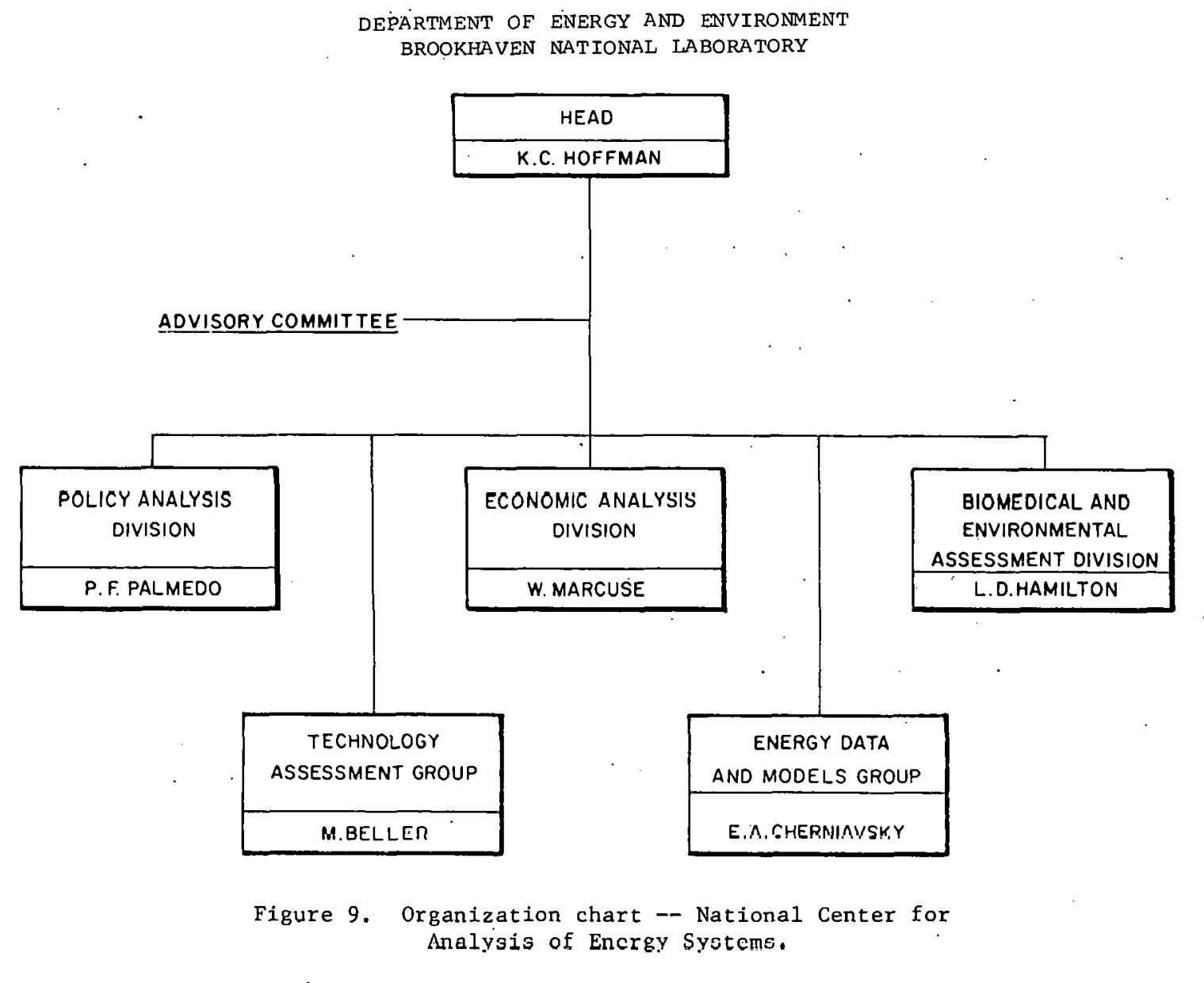

$-28-$ 
the NSF Science and Technology Policy office, and the Department of Commerce. A close working relationship has been established with energy groups at stanford, Princeton, Harvard, MIT, the University of Illinois Center for Advaneed Computation, the Electric Power Research Institute, and several other universities and institutions.

Extensive interactions and collaborations have also been established with the International Institute of Applied Systems Analysis in Austria, the International Energy Agency, the Commission of European Communities, and the Environment Directorate of the OECD. These relationships provide useful points of contact for the international aspects of the Center's programs.

\section{SCOPE OF ACTIVITIES}

The activities and responsibilities of the major groups in the Center are outlined below. These activities are closely integrated and specific studies generally involve personnel, from several groups working under the direction of a Principal Investigator or Program. Manager.

\section{Polijey Analysis}

The activities in the area of Policy Analysis have focused on international programs and on regional studies including detailed study of the use of energy in urban areas. The scope of the regional energy/environmental study has been expanded to cover the Northeast region of the U.S." with particular attention to the urban megalopolis. The energy/environmental studies are performed in the context of planning for the social and economic development of the region and provide detailed insight into problems of implementing technologies once they are developed.

Specific studies in thi.s activity include:

1. Energy demands and environmental implications in the New York City and Northeast region. 
2. Forecasting of regional energy demands and strategies.

3. Energy implications of regional development and patterns of land use.

4. Development of analytical models for regional energy/ environmental planning and land use.

5. Siting of major energy-related facilities with analysis of environmental implications.

6. Special studies of international scope dealing with energy technology and policy issues in developing countries.

7. Systems analysis of cooperative R\&D programs for the International Enerqy Aqency.

\section{Economic Analysis}

Comprehensive energy planning and analysis requires detailed study of the economic characteristics of energy technologies and of the relationship of energy to the social and economic structure of the nation. The objective of the Economic Analysis activity is to analyze these relationships ensuring that the technological realities of the energy system are reflected in economic modeling and analysis. Support is provided to the Technology Assessment work in economic analyses used for projections of energy demand and in the analysis of the economics of new technologies.

Specific activities in the area of Economic. Analysis include:

1. Economic analysis of interfuel competition and role of energy in various sectors of the U.S. economy.

2. Model development involving Input-output and macroeconomic model's that are used for economic analysis and planning.

3. Analysis of shadow prioes and coet-bcncfit charac teristics of new technologies.

4. Cost studies of advanced technologies under conditions of changing cost of inputs to production. 
5. Projections of level of economic activity and related energy requirements.

6. Identification and analysis of nontechnological alternatives to technical solutions.

7. Studies of commercialization and the identification of socio-economic effects of technology implementation.

8. Special studies in areas of net energy or energy accounting.

\section{Biomedical and Environmental Assessment}

The biomedical and environmental impacts of energy supply and utilization must be considered explicitly in analysis and planning at both the national and regional levels. The objective of this assessment work is to identify all of the externalities, or, social costs, associated with the extraction, conversion, transmission, and use of alternative fuels and energy sources. Some of these externalities are easily identified and quantified; others are not well understood. The assessment provides information on biomedical and health effects to an overall assessment of energy technologies and policies in which social, economic, and environmental factors must be balanced. The work also serves to identify information gaps on the spatial transport, conversions, and biological damage associated with pollutants or externalities that must be resolved through research in such areas as atmospheric dynamics, health. effects, ecology.

Specific activities in Biomedical and Environmental Assessment include :

1. Assembly of quantitative information on pollutants and other externalities associated with specific fuel cycles and energy conversion technologies.

2. Analysis of transport and damage associated with various pollutants. 
3. Analysis of morbidity and mortality in areas of different air quality, including identification of life-shortening effects.

4. Studies of site-specific impacts of energy systems and of other special policy topics.

\section{Technology Assessment}

The activity in this area is intended to provide a continuous assessment of the state of development and likely impact of new energy technologies and to perform studies of interfuel substitution. The scope of the assessments includes technologies and processes for all fuels and energy forms and all activities from extraction to end use as indicated on Reference Energy Systems (RES). The RES indicates reference or existing technologies with which new technologies must compete. Impacts of new energy technologies are measured against Refexence Energy Systems that project the technical structure of the energy system along with costs and environmental impacts through the year 2000. A unique feature of the methodology is the inclusion of the load structure of specific electrical demands and the incorporation of end-use technologies (air conditioners, combustion devices, engines, etc.) at the same level of detail as energy supply technologies. The latter is frequently a limiting factor in the rate of implementation of alternative energy systems and in energy conservation.

Future scenarios of the implementation of groups of technologles and new resources are developed. The socio-economic and environmental consequences are analyzed in detail and impact analybub art perfurmod.

Specific responsibilities in this area include:

1. Projection of future energy demands and fuel mix as represented in the Reference Energy system. 
2. Optimization studies to determine the most effective utilization of new technologies and to evaluate interfuel substitution strategies.

3. Estimates of likelihood of success and implementation of new technologies.

4. Development of technological strategies for the implementation of new energy systems.

5. Process analysis of new energy technologies and energy: intensive production activities.

6. Special studies in energy intensive activities such as materials, agriculture, and transportation.

\section{Energy Data and Models}

The Energy Data and Models activity provides a central capability to coordinate and integrate energy data bases and analytical modeling. Close coordination is maintained with university and industry groups developing data and models of interest for energy policy.

A comprehensive data base, the Energy Model Data Base (EMDB), is maintained at Brookhaven. This data base was developed under the auspices of the Council on Environmental Quality, Energy Research and Development Administration, National Science Foundation, and Environmental Protection Agency. The EMDB is available to governmental, industry, and univeraity groupa. The disacmination of the . data on energy technologies that are contained in the EMDB provides a uniform and consistent basis for energy policy studies performed by these diverse groups. It also ensures that differences in policy recommendations may be attributed to the viewpoint of the group and not to differences in supporting data obtained from the data base. The Data and Models activity also supports the studies performed within the Center at Brookhaven. 
Included in the EMDB are:

1. Technical efficiencies and fuel requirements of 400 energy supply processes and 200 end uses.

2. Emissions (air and water), occupational házards, waste, and costs of individual processes and end uses.

3. Labor, material, and water requirements of supply

processes.

Individual data elements (efficiencies, emissions, cost) may be extracted from the data base for each process. This information may be aggregated to provide a summation of elements associated with a given energy trajectory, e.g., coal to iron and steel production; a subsystem, e.g., alluses of coal; or the complete Reference Energy system as projected for some future planning period. Responsibilities of the Energy Data and Mödels activity include:

1. Coordination and integration of energy data and models.

2. Maintenance, verification, and update of the Energy Model Data Base.

3. Maintenance and development of the energy system models used in the energy programs.

4. Assistance to federal, state, and local government agencies, universities, and industry in the use of data and models when such assistance is related to a Brookhaven program.

5. Special data and analysis tasks in support of other programs within and external to the center.

A tabulation of Inergy Data Dases and Analytical Models developed by or available to the center through collaborative agreements is given in Appendix B. The policy of the Center is to rely wherever possible on the developer to perform analyses with his data base or model. This policy is based on the belief that the 
group which developed the model is in the best position to understand and interpret the policy implications of a particular model. Thus, any requests for information and/or analyses with data bases or models developed elsewhere should be made directly to the developing group or institution. 
,THIS PAGE

WAS INTENTIONALLY

LEFT BLANK 


\begin{abstract}
APPENDIX A
SCOPE OF ACTIVITIES FOR FY 1978

AT THE

NATIONAL CENTER FOR ANALYSIS OF ENERGY SYSTEMS
\end{abstract}


A. Policy Analysis--Energy and Economics 
Title: Systems Studies and Analyses.- Energy Systems studies (Areas 1, 2, and 3)

FY 78: $\quad \$ 1,375,000$

Principal Investigator (s):

FY 79: $\$ 1,700,000$

E. A. Cherniavsky, M. Beller, and D. Behling

Sponsor: Assistant Secretary

for Policy and Evaluation and

Energy Information Administration

The Energy Systems Studies program encompasses a broad range of energy studies for the development of research and development priorities and strategies. The program involves the development and coordination of energy data and analytical models and the application of these techniques to energy systems analysis, technology assessment, and economic analysis. It is carried out within the National Center for Analysis of Energy Systems (NCAES).

The Energy Systems Studies program involves work in three major areas.

Area 1 - Energy Models: Coordination and development of U.S. energy system models applicable to the DOE planning and analysis. function. The work in this area involves the maintenance and application of the Reference Energy System (RES) and the Brookhaven Energy System optimization Model (BESOM) and the evaluation nf energy models developed elsewhere that may be applied to DOE studies alone or in combination with BESOM.

Area 2 - Technology Assessment: Analysis of fuel substitution strategies and the technical characteristics of energy technologies. This work involves the use of the RES as a framework for analysis supported by energy syatems (Area I) and economic modeling (Area 3). Special studies are also performed of implementation opportunities and technological trends in other countries. 
Title: Systems Studies and Analyses - Energy Systems Studies (Areas 1, 2, and 3)

Area 3 - Economic Analysis: Analysis of interrelationships between energy and the economy. This work involves the development of economic models that can incorporate technological detail, and their application to DOE planning activities and special policy studies. 
Title: Systems Studies and Analyses - Environmental and Socioeconomic Support Program

FY 78: $\$ 300,000$

Principal Investigator(s):

FY 79: $\$ 400,000$

E. A. Cherniavsky

Sponsor: Assistant Secretary

for Policy and Evaluation

The Environmental and Socioeconomic Support Program is designed to provide assistance to the office of Policy and Evaluation of DOE in its task of supplying input to the National Energy R\&D Plan regarding the environmental and socioeconomic impacts of alternative energy $R \& D$ strategies. The program focuses on the bringing to bear of many of the capabilities of the National Center for Analysis of Energy Systems (NCAES) on the assessment of such impacts.

The analysis of environmental and socioeconomic factors resulting from the future emplacement of energy-related facilities is complex and requires access to a variety of analytic tools. Since the impacts of these factors are experienced differently in different areas of the country, a regional approach is essential. Utilization of optimization and flow models of the energy system, and of models of the national and regional economies provide measures of the direct economic costs and benefits of the terhnological. aspects of the energy supply and demand systems. An understanding of the emissions and health effects of the fuel cycles involved is required in order to assess the environmental effects of providing energy in its various forms. Choices of future energy options require detailed study of the interrelationships of regional characteristics and resources and the available technologies. Underlying all of these techniques is the need for highquality numerical data which characterize the technology of energy 
Title: Systems Studies and Analyses. - Environmental and Socioeconomic Support Program

related processes, the structure of the economy, and the impacts on the environment of energy activities. One source of such data is the Energy Model Data Base which will be maintained, updated, and expanded as part of this program. It has become a national facility and will continue to be made available to outside users. In addition, othor eources of information, required by the proqram will be accessed or acquired and integrated with the analytic capabilities. 
B. Program Level Planning and Analysis 
Title: Economic, Policy and Planning Analysis, Program to Assess the Potential for Geothermal District Heating

FY 78: $\$ 150,000$

Principal Investigator(s): J. Karkheck; R. Tessmer, Jr.

FY 79: $\$ 225,000$ Sponsor: Economic Policy and Planning office, Division of Geothermal Energy

The purpose of this study is, first, to develop and apply techniques for estimating the economic feasibility for meeting such demands with geothermal heat sources and the extent and nature of such markets. Secondly, this study will identify and examine institutional factors which might affect adoption of such technology. Relevant factors include the monopoly and regulation aspects of existing public utilities, formation and regulation of competitive public utilities (i.e., geothermal), and behavioral constraints or reactions to such things as unfamiliar home heating equipment and pipe laying.

The term "diatrict hoating," as it is used here refers to the supply of direct heat from geothermal sites, by a utility, to multiple users. Potential markets for district heating include residential and commercial demand for water heat and space conditioning. industrial and commercial demand for low temperature process heat, and agricultural/fishery demand for low temperature process heat and drying. In order to evaluate the economic feasibility and extent of these markets, this activity will encompass both the supply side (bringing heat to the consumer), the demand side (retrofitting and/or end use capital equipment), and competing, conventional technologies.

Special analysis techniques will be employed to assess potential markets for geothermal district heating. 
Title: Economic, Policy and Planning Analysis, Program to Assess the Potential for Geothermal District Heating

Behavioral patterns of potential consumers are also important in that they could affect acceptance and utilization of a district heating system. What is known is generally preferred to what is unknown. To residential consumers, district heating might mean installation of unfamiliar heat transfer equipment, the reliability and maintenance of which must be examined. For industrial consumers a district heating commitment might engender additional real economic costs because of competing objectives of each firm. Such factors will be identified within this portion of the program so that they can be assessed in terms of their real economic cost to consumers and, where possible, overcome through an effective marketing plan for a proposed district heating system. 
Title: Analysis and Use of Transportation Energy Models

FY 78: $\$ 140,000$

Principal Investigator(s):

FY 79: $\$ 150,000$

J. R. Wagner

Sponsor: Division of Transportation Energy Conservation

The Division of Transportation needs quantitative tools to measuxe the impact of alternative transportation energy conservation projects. Quantification is necessary both for internal budget allocation and for supporting ita ovcrabl program ishen raviewed by OMB and DOE.

The Brookhaven Energy System Optimization Model (BESOM) is a quantitative tool used to help generate DOE's annual plan. BESOM is generally too aggregated to provide meaningful analysis of a particular transportation energy conservation project designed to deal with an individual transportation mode. However, there do exist computer models, developed by the Department of Transportation and others, that permit detailed analysis of separate modes.

It ig the purpose of this project to acquire appropriate modal models and to integrate them into BESOM and other macro-energy. models. The result will be a system that can evaluate the impact of individual projects in a mannex consistent with the overall DOE plan. 
Title: Conservation Policy and Program Analysis

FY 78: $\$ 230,000$

Principal Investigator(s):

W. Marcuse

FY 79: $\$ 260,000$

Sponsor: Office of Conservation Policy \& Programs

This program is directed to answering three vital questions: (a) Why should the nation support conservation programs?; (b) Given that conservation programs should be supported, which ones should be chosen?; and (c) Having chosen the desired programs, how can they best be carried out?

The first major component is identification and assessment of the basis for national activities in the area of energy conservation. A continually evolving document, "Foundations of Energy. Conservation Policy," sets forth the rationale to assist in overall policy formulation and to support conservation policies. The second component will provide a systematic framework for program evaluation and selection. Criteria to be used for determining priorities both among and within areas are identified. The third component provides. CPP with the capability to encourage adoption and use of energy conserving procedures and equipment and to recommond and support broad conservation policies. 
Title: Industry Conservation, Assessinent of Conservation options

FY 78: $\$ 200,000$

FY 79: $\$ 220,000$
Principal Investigator (s):

W. Marcuse

Sponsor: Division of Industry Conservation

U.S. energy policy is directed toward increasing domestically supplied energy through the development of new energy supply ronversion options and decreasing energy demand through energy conservation options. Tools and methodological approaches have been developed which have been useful in assessing tie value of propood supply technologies. This program is directed to the extension, improvement, and modification of these tools for use in the assessment of industry conservation options.

The Division of Industry needs analyses of specific projects in order to provide balance to its internal budget allocation and to quantitatively support its program. This program includes both the evaluation of projects on an ad hoc basis using existing methors and the extension of existing'models to give more thorough and specialized evaluatiun of industrial conservation technologies. 
Title: Assessment of Building and Community System. Conservation Options

FY 78: $\quad \$ 125,000$

FY 79: $\$ 200,000$
Principal Investigator(s):

S. Carhart

Sponsor: Division of Buildings and Community systems, Systems Analysis Branch

The purpose of this program is to modify and extend analytical tools originally developed for use in assessing the value of proposed supply technologies to permit their use in assessment of conservation options. The specific tools involved are an energy network diagram known as the Reference Energy System and the Brookhaven Energy System Optimization Model, which is a linear programming model of the U.S. energy system. The extensions will be accomplished mainly by substantially.increasing the level of detail in the end use areas. The models will be extended and applied to the Buildings and Community systems (BCS) area. Capabilities of the developed models will include (I) cost benefit analysis of specific conservation options, (2) definition of design objectives for new end-use devices, (3) analysis of environmental, resource, and oil import benefits from new technology or policy implementation, and (4) providing a basis for the analysis of social and economic consequences of conservation options.

This program will build on previous efforts and provide more accurate information for management of conservation programs by improving the descriptione and data concerning profects within the model framework. It will also draw extensively on other BCS planning, analysis, and evaluation activities to obtain better understanding of conservation programs and more accurate inputs to analyses conducted under this program. 
Title: Systems Studies Support Program - Fossil Energy

FY 78: $\$ 200,000$

Principal Investigator(s):

FY 79: $\$ 285,000$

E. A. Cherniavsky

Sponsor: Office of Fossil

Energy

The objective of this program is to provide analytical support to the Fossil Energy Strategy Development. This support involves the continuing assembly, qualification, updating, and application of data bases and analytical tools that describe the technical, environmental, and economic characteristics of fossil energy technologies and fossil energy resources. When required, the relationship of fossil energy to other energy sources, its interaction with the U.S. economy and international trade, and impacts on it of institutional constraints are explored. The primary users of these data and analysis tools are DOE and Brookhaven personnel; access is provided to others as LRSD needs dictate: 
Title: Energy Storage Systems Analysis

FY 78: $\$ 180,000$

Principal Investigator(s):

M. Beller; J. Schank

FY 79: $\$ 195,000$

Sponsor: Division of Energy

Storage, Assistant Secretary

for Energy Technology

The objectives of the program are to provide analytical support to the Division of Energy storage in terms of impact assessments of selected technologies and specific assignments requested as they pertain to energy storage programs. Additionally, studies of storage applications, with particular emphasis on solar technologies, will be performed. The general approach is to study energy storage options as functions of fossil fuels prices and availability, device cost and availability, and off-peak power supply and cost. The national impacts of storage technologies commercialization, in terms of total costs, electric and nonelectric fuels supply mix, electric load factors, and environmental emissions, will be determined. The results will be applicable to guiding DOE RD\&D programs and to assisting in energy policy formulation. Opportunities for fuel savings attainable by the use of storage devices in all sectors of the energy system will be explored. 
C. Regional Programs

$$
\text { Regional Programs }
$$


Title: Assessment of Impacts of Energy Production:on Local, Regional and National Scales - Regional Energy. Studies

FY 78: $\$ 605,000$

FY $79: \quad \$ 685,000$
Principal Investigator(s): P. Meier, P. Palmedo

Sponsor: Assistant Administrator for Environment and Safety, Division of Technology Overview

The objective of this program is the development, testing, and application of data, models and assessment tools for regional energy planning. It is part of an integrated multi-laboratory effort aimed at critical energy planning problems requiring analysis at the regional (multi-state) scale. The primary outputs of the program are a series of policy analyses and a set of evaluation tools that can be used by state, local, and regional agencies as well as utilities and industrial groups with interests in energyrelated planning.

The Brookhaven National Laboratory (BNL) program is structured into three main components: (1) a program of regional liaison, emphasizing the establishment of an energy planning and analysis partnerhsip with each of the states in the northeast; (2) a program of integrated regional assessments, addressing key regional energy issues with particular concern for environmental and health impacts and the analysis of complex trade-offs between environmental quality, economics, national security, social impacts, institutional questions, and technical considerations; and (3) a program of special studies, addressing methodological and policy questions, and including technical support to other regional studies programs. 
Title: Assessment of Impacts of Energy Production on Local, Regional and National Scales - Regional Energy Studies

Currently, the regional assessment program is addressed to six major areas: An evaluation of the relationships between energy system development and the regional economy; an assessment of conservation issues; an assessment of the problems of energy systems in urban areas; assessment of increased coal utilization in the northeast with special emphasis on air quality and health impacts: analysis of issues assoclated with uff-sluse eireigy development. in the northeast; and an assessment of the relationship of energy development to water resource constraints and water quality, especially in the context of increasing competition from water supply and recreational use in an area of high population density. 
Title: Assessment of Impacts of Energy Production on Local, Regional and National Scales - Technology Impact Assessment

FY 78: $\$ 495,000$

Principal Investigator(s) :

P. Meier, P. Palmedo

FY 79: $\quad \$ 565,000$

Sponsor: Assistant Administrator for Environment and safety, Division of Technology Overview

The technology impact assessment program within the Integrated Assessment Program of DOE's/Administrator for Environment and safety (AES) is designed as a close adjunct to the Regional studies Program, and has as its major objective the detailed national/regional analysis of the environmental impacts and trade-offs of alternative energy system futures. This is to be accomplished by a series of regional scale assessments, integrated to the national level, for each major energy technology, including conservation.

The Brookhaven program calls for two types of contributions: lead laboratory assignments in the areas of conservation assessment and inter-fuels comparisons, and a support role for other fuel assessments. In the lead laboratory role, the geographic focus will be national, with regional inputs from the other laboratories as necessary; in the support rnle artivitiee, the geographic fucus coincides with that of the Regional studies Program, namely the northeast.* In FY 1978 Brookhaven will conduct: (1) a National Conservation Assessment as its lead laboratory responsibility, and (2) the northeastern portion of the National Coal utilization Assessment.

*Defined as the New England States, New York, New Jersey, Pennsylvania, Delaware, Maryland, and the District of Columbia. 
Title: Emissions Policy Analysis Support

FY 78: $\$ 70,000$

Principal Investigator(s):

FY 79: $\$ 16,000$

J. P. Brainard

Sponsor: Division of Transportation Energy Conservation

The objective of this project is lo verify and analyzo data, develop and apply models and other policy assessment tools, in order to identify and quantify important determinants of automobile use and associated environmentâl Impacts ln Llıe New rovk City region.

The project will include analysis of how the levels of direct and indirect automobile energy. consumption and automobile emissions are affected by various land use and taxation policies. Brookhaven's responsibility will be to assist the office of conservation of DOE in the coordination and supervision of this project, particularly as it relates to the objectives of the Regional Energy Studies Program. 
D. International Programs 
Title: Systems Studies and Analyses - IEA, Systems Analysis Program, Phase II

FY 78: $\$ 300,000$

FY 79: $\$ 400,000$
Principal Investigator (s): V. L. Sailor

Sponsor: Office of Energy Research

Brookhaven National Laboratory (BNL) has been serving as the U.S. site for the systems analysis program of the International Energy Agency (TEA). The objective of this program is to develop data and perform analyses of the impact of new energy technologies. on the energy systems of member IEA nations and thereby establish a basis for research and development (R\&D) strategy. The Kernforschungsanlage (KFA)-Julich has been serving as the European site for this program and close coordination has been maintained between the two groups. The Directors of each group report to the IEA Steering Group for Energy R\&D Strategy established for the Systems Analysis Program.

This schedule 189 and budget covers the BNL appointee aind support staff to the program as well as materials, supplies, services, overhead and management expenses associated with the activity at BNL. A more detalled work plan has been developcd for the activity by the steering Group and has been reviewed and updated at about 3-month intervals. A number of representatives, assigned to the IEA Systems Analysis staff by member IEA natiuns arrived at BNL in May 1976. The salaries, living expenses, and travel of these representatives will be covered by their home countries and are not included in this budget. Under the new BNL policy on "Medical Insurance for Foreign Visittors," the costs of. medical insurance for the non-paid guests will be covered during their time of residence on site. 
Title: Systems Studies and Analyses - IEA, Systems Analysis Program, Phase II

The BNL staff appointee selected by the Steering Group serves as the program director. Another BNL staff appointee serves as the United States representative. The support staff (also BNL employes) report to the Director and provide assistance in the work plan. BNL expert consultants provide special technical services.

The IEA Steering Group has requested that the supporting staff expand the scope of their efforts to include in the systems analysis program various IEA member nations not actively participating in the program. This will require one man-year per year of addtional BNL staff support.

$-59-$ 
E. Biomedical and Environmental Effects Programs 
Title: Assessment of Health Effects of Energy Systems - Assessment. of Biomedical and Environmental Costs of Energy Systems

FY 78: $\$ 685,000$

FY 79: $\$ 1,010,000$
Principal Investigator (s):

L. Hamilton

Sponsor: Division of Technology Overview/Environment

This program aims at developing a systematic overview of biomedical and environmental costs of energy production and use. All forms of energy are being considered. Starting with a compilation of residuals from the energy system, the various pathways to man are traced. This task entails definition of transport mechanisms including chemical conversions and various links through the biosphere to man. An evaluation is then made of effects. The initial focus is on biomedical effects and environmental effects on animals, crops, other vegetation, and on land, known to affect man. This evaluation relies on available information; epidemiological data, field and laboratory studies carried out on appropriate animals and vegetation, and basic biomedical research designed to elucidate molecular and cellular mechanisms underlying biological responses to various residuals. By taking account of the magnitude of energy flow through the gygtem and of the populations exposed, total effects are calculated. The basic framework of the evaluation is provided by the national energy system models and data base in use and under development by the National Center for Analysis of Energy Systems (NCAES) at Brookhaven. That work provides a significant resource for this program and a means of integrating the results of the program into national energy policy analysis. 
Title: Assessment of Health Effects of Energy Systems - Assessment of Biomedical and Environmental Costs of Energy Systems

Integrated assessment activity in this area is designed to serve two purposes: (I) guide the allocation of resources in the biomedical research program, and (2) provide information on biological and environmental costs required to make decisions regarding alternative energy systems. 
Title: Environmental Policy Analysis - Analysis of Energy and Environmental Policy Considerations

FY 78: $\$ 280,000$

Principal Investigator (s):

FY 79: $\$ 350,000$

L. Hamilton

Sponsor: Assistant Secretary for Environment

This program will provide the Department of Energy (DOE) with dissections of relationships among technical, environmental, health, economic, and societal factors as they affect environmental regulation, energy, and environmental R\&D policy, or the commercialization of developed energy systems. The program entails longer-term policy analyses to diagnose incipient energy/environmental problems and short-term studies to meet policy-making needs in DOE.

The DOE/Assistant Administrator for Environment and Safety (AES) environmental policy analysis program indentified two major tasks: Task 1 is a review and evaluation for the identification of potential conflicts between energy development and environmental/ use policies; Task 2 is the analysis of critical issues identified in Task 1 as assigned by AES/Office of Environmental Policy (OEP). This Schedule 189 covers Task 1. Revisions will be prepared as required to cover activities under Task 2 . 


\section{APPENDIX B}

\section{DATA BASES AND ANALYTICAL MODELS \\ DEVELOPED BY AND/OR AVAILABLE TO THE CENTER}

The work performed in NCAES includes technical, economic, environmental, and policy analysis of all aspects of the energy system. In this work, a mix of quantitative and nonquantitative information must be utilized. Depending on the policy issue to be addressed, the analysis and interprelalion of quantitative information can comprise anywhere from perhaps $10 \%$ to $90 \%$ of the policy study. To assist. in this portion of the work, a number of data bases and analytical modeis have been dsselluled al llie center. The scope of the assemblage of data and models is shown in Figure B-l. This figure illustrates the relationships between the economy, the energy system, and individual technologies that must be addressed in a complete analysis. The basic structure of the Brookhaven energy system-models is represented in Figure B-2, The Reference Energy System. The capital, labor, energy, and material resources on which the energy system and economy is based must be considered. Also, environmental and health effects of technologies must be addressed and these factors, combined with the state-of-theeconomy, comprise the society and lifestyles that are uppermost in the planning and analysis hierarchy. The data bases and models listed below address various components of the hierarchical system and the relationships among the components.

Some of the models listed were developed by other groups and are available to Brookhaven through collaborative activities. The policy of NCAES is to, wherever possible, work with the model developer in a collaborative way such that the developer performs the actual runs or analysis with his model. Therefore, anyone interested in a model or data base listed here that was developed elsewhere should contact the developer for any information or possible application. 


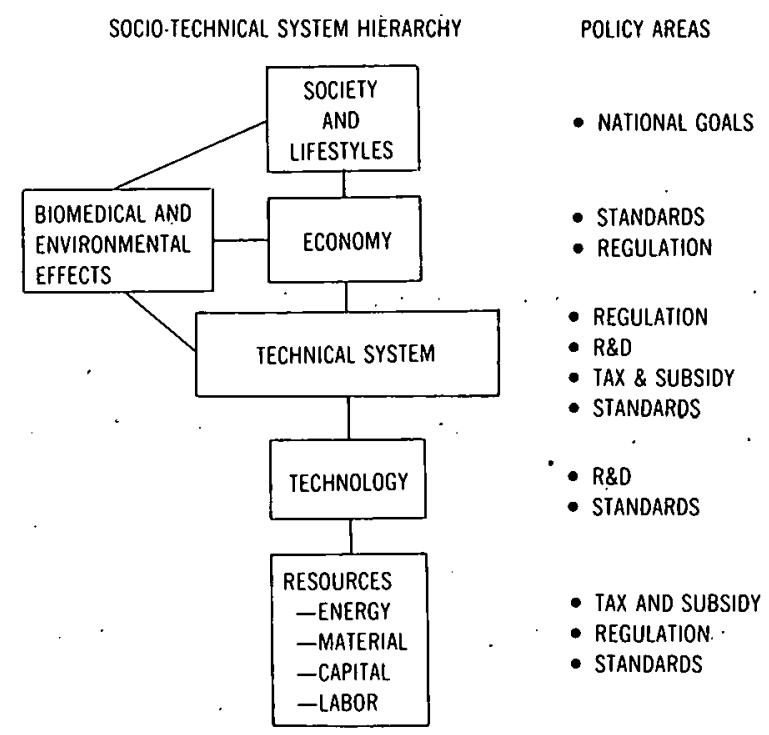

Figure B-1. Policy considerations.
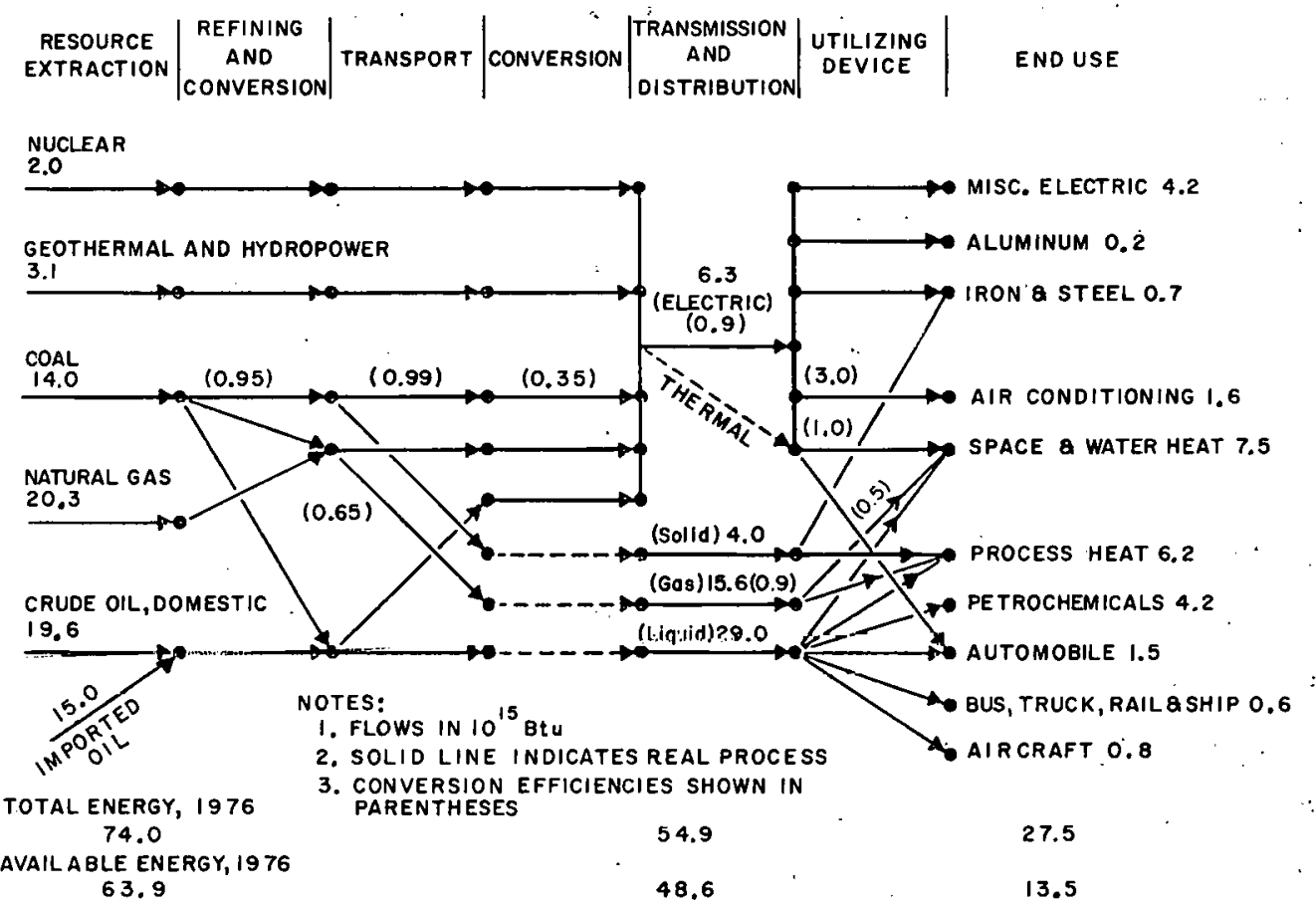

Figure B-2. Reference energy system. 


\section{ENERGY SYSTEMS}

Models:

1. Model: Brookhaven Energy System Optimization Model (BESOM) Developed By: Brookhaven National Laboratory Status: Operational on CDC 7600 - Brookhaven National Laboratory Description: A linear pruyiamming model of the national energy system emphasizing technological detail and interfuel cubstitutinn which focuses on a single year at a time.

2. Model: Dynamic Energy System optimization Model (DESOM) Developed By: Brookhaven National Laboratory Status: Operational on CDC 7600 - Brookhaven National Laboratory Description: A linear programming model of the national energy system emphasizing technological detail and interfuel substitution which optimizes over a time horizon (usually 10 5 -year periods).

3. Model: Regional Energy System for the Planning and optimization of National Scenarios (RESPONS) (also known as the Bechtel Coal Model)

Developed By: Bechtcl Corporatinn Status: A version that will be operational on the Brookhaven Naliulal Inboratory $\mathrm{CDC} 7600$ is under development Description: A linear programming model of the national energy system with special emphasis on the coal sector. 
4. Model: Multi-regional Energy System Optimization Model (M-RESOM) Developed By: Brookhaven National Laboratory

Status: Development is complete and the model is being validated

Description: A multi-regional ( 9 census regions) version of Brookhaven Energy System Optimization Model (BESOM).

5. Model: CURVE

Developed By: T. Muench, M. Wooders, R. McLean of SUNY Stony Brook

Status: Operational on UNIVAC at SUNY Stony Brook Description: "Calculates demand for fuel and fuel systems required to heat single family dwelling units."

6. Model: Federal Energy Agency Marketing and Mobility Model Developed By: Jack Faucett Associates

Status: Operational on U.S. Department of Energy's (DOE's) Germantown computer.

Description: Computes size of auto fleet to year 2000. and indicates fuel consumed and vehicle miles traveled.

7. Model: Auto Fleet Submodel

Developed By: Department of Transpnrtation

Status: Operational on U.S. Department of Energy's (DOE's) Germantown computer.

Description: Computes size of auto fleet to year 2000: miles traveled, and fuel consumption by grade of fuel,

8. Model: Bruokhaven Energy Transportation Submodel Developed By: Brookhaven National Laboratory

(Cont'd) 
8. Status: Operational on CDC 7600 - Brookhaven National Laboratory

Description: Calculates energy requirements for the transportation of energy.

9. Model: Industry Process Optimization Models Developed By: T. Sparrow at Brookhaven National Laboratory Status: Under development on Brookhaven National Laboratory CDC 7600

Description: Linear programming models of the iron and steel, cement, aluminum, and paper and pulp industries have been

- completed. Sensitivity of market penetration to capital costs and energy prices may be examined.

10. Model: 'Energy Supply-Demand Scenario Model

Developed By: Brookhaven National Laboratory from Oak Ridge International Energy Agency (IEA) work. .

Status: Leveloped: description arists in Northeast Perspectives Reports

Description: Allows matching of independently developed supply and demand scenarios. Creates ail em1sglum! irvontory;

11. Model \& Data: Con-Ed Generation Model for Load Management Developed By: Consolidated Edison Company, modified by Brookhaven National Laboratory ( $J$. Alleriluck)

Status: Operational-Brookhaven - National Laboratory CDC 7600 Descripliun: Simulatce Gunmir niapatoh of CON-ED electric generation. The model is driven by time-varying load curves developed on the basis of aggregating electric demand in the CON-ED service area by end use. 
12. Model: Time-Stepped Energy System Optimization Model (TESOM) Developed By: Brookhaven National Laboratory

Status: Operational on CDC 7600 - Brookhaven National

Laboratory

Description: A "myopic" time-phased model which optimizes over the changes possible from one time-step to the next. No knowledge of the future is assumed, permitting improved simulation capability.

13. Model: Brookhaven Energy Conservation Optimization Model (BECOM)

Developed By: Brookhaven National Laboratory

Status: Operational on CDC 7600 - Brookhaven National Laboratory

Description: Assesses both new and retrofit conservation technologies in nine building types and four regions.

14. Model: Preparation of Reference Energy Systems Through Time (PRESTO)

Developed By: Brookhaven National Laboratory Status: Completed, operational on CDC 7600 - Brookhaven National Laboratory

Description: Interactive computer program (based on the RefEnergy system) that provides a convenient framework for energy flow accounting over time.

15. Model: Regional Process Heat Model (BEPHOM)

Developed By: Brookhaven National Laboratory Statue: Completed, operatiunal on CDC $/ 600$ - Brookhaven National Laboratory

(cont'd) 
15. Description: This extension to the BESOM model was developed to permit more realistic analysis of the use of solar and geothermal energy resources in the process heat sector. BEPHOM disaggregates the total process heat demand into four regional categories and five temperature regimes within each region. The four regions are consistent with those employed in BECOM. The temperature regimes were chosen to correspond to four collector/fluid combinations (air, low temperature; air, high temperature; steam, low temperature; steam; high temperature) plus one rciidual category for which solar is not permitted to compete. A backup supply is required in all solar applications. 'lhe following parameters can be varied independently for each region/temperature combination: the capital costs of the collectors, per square foot, the efficiencies of conversion of solar to thermal energy, the number of square feet required per million Btu's per year of output, the fraction of solar to backup power.

\section{Data Base:}

1. Data Base: Energy Model Data Base Developed By: Brookhaven National Laboratory

Status: Operational on Brookhaven National Laboratory CDC 7600 Description: Includes (costs, efficiencies, and environmental effects of) new and old technological processes for both supply and utilization.

2. Data Base: County Energy Data Base (COENDA)

Developed By: Brookhaven National Laboratury (C. Calef, and F. Drysdale)

Stalus: Completed, periodically updated and revised, computerized, manipulated by County Energy Budget (COENBU) Program. 
2. Description: Contains county and state level energy, economic, and environmental data. State level data are disaggregated in many instances to provide estimates of county level parameters.

3. Data Base: New York City Data Base

Developed By: Brookhaven National Laboratory

Status: Data exist in a series of Brookhaven National Laboratory reports

Description: Energy and environmental data related to New York City.

Client: New York City Government

4. Date Base: Northeast Region state Level Data Base Developed By: Brookhaven National Laboratory and Subcontractors Status: Data exist in the Northeast Perspectives Reports Description: Energy and Environmental Data for all states in the Northeast Region.

Client: State Energy-Environmental offices, United States Department of Energy. Brookhaven National Laboratory for Policy Analysis

5. Data Base: 100 Power Plants Data Base Developed By: Sam Morris and Granger Morgan, Brookhaven National Laboratory

Status: Completed, computerized on CDC 7600 - Brookhaven National Laboratory.

Dcscription: Demograplic lata within 100 miles of 100 power plants in the United States, mostly in Northeast.

Models : ECONOMY

1. Model: Data Resources Incorporated Long-Term Inter-Industry Transactions Model (cont'd) 
1. Developed By: Data Resources Incorporated

Status: Operational in conjunction with Data Resources Incorporated on their computer

Description: Combined macro-economic and inter-industry model. Contains econometrically estimated production and utility functions. Permits simultaneous determination of relative prices and input purchase patterns over time.

2. Model: Integrated BNL/DRI Model for Long Term Energy/Economic Analysis

Developed By: Brookhaven National Laboratory and Data Resources Incorporated

Status: Operational on the CDC 7600 at Brookhaven National Laboratory via iterative solution procedure. Linkage equations being programined.

Description: The Data Resources Incorporated Long Term Interindustry Transactions Model is coupled with the Brookhaven Time-Phased Energy System Optimization Model (TESOM) and attached energy supply schedules.

3. Model: Input/Output Model

Developed By: Brookhaven National Laboratory and Center for Advanced Computation; University of Illinois

Status : Static and Dynamic Prime Versions operations on CDC 7600 at Brookhaven National Laboratory; dual pricing model $50 \%$ complele

Description: Energy transactiuns are definea in tcrme of rusctional service units. Engineering-based production functions are added for a wide variety of energy supply and conversion technologies. Operational extensions include incorporation of a capital matrix for two period dynamic solutions and a balance of payments routine. 
4. Model: Input/Output and Energy System Optimization Model Developed By: Center for Advanced Computation, University of Illinois, and Brookhaven National Laboratory

Status: Operational on CDC 7600 at Brookhaven National Laboratory and at Center for Advanced Computation, University of Illinois

Description: An energy input/output model with 102 producing sectors is coupled with Brookhaven Energy system optimization Model (BESOM) to permit interfuel substitution. Extensions under development include a reduced form, which will not require iteration between the Input/output and Brookhaven Energy System Optimization Model, and a multi-regional input/output model.

5. Model: Model for the Assessment of Uncertainty and Risk Developed BY: Peter Love for OECD and International Energy Agency (IEA)

Status: Completed

Description: Uses decision analysis and Monte-Carlo methodology to assess the uncertainty and risk involved in the assessment of new technologies.

6. Model: Analysis of the Impast of Now Energy Tcchnologies in an overall system

Developed BY: Peter Love for OECD and International Energy Agency (IEA).

Status: $90 \%$ complete

Description: A methodology for ranking specific technologies within some given system and with estimated upper and lower implementation bounds. 
1. Data Base: New York State Energy-Economic Data Base Developed By: SUNY at Stony Brook (Owen Carroll and John Sanborn) and Brookhaven National. Laboratory

Status: Under development

Description: Energy and Economic data for New York State. Plan to use a modified Energy System Network Simulator (ESNS) to interface with data.

Client: New York State Energy Research and Development Administration, New York State Energy office

ENVIRONMENT

Models:

1. Model: Energy System Network Simulator (ESNS)

Developed By: walter A. Sevian, Brookhaven National Laboratory

Status: operational on Brookhaven National Laboratory CDC 7600 Dcccription, A flow model whirh is a net:work representation of national or regional energy systems. Extensions include an operational model for nuclear fuel cycle analysis which relies on a data base on nuclear and some nonnuclear technologies, developed by Teknekron. The current working version has 435 supply and end use processes.

2. ModeL: Radiological and Blologiad Generie Almublitia Dose (RABGAD)

Developed By: Teknekron, Incorporated Status: Operationdl on Bruukliaven Nalional Laboratory CDC 7600 Description: Transport model 
3. Model: Energy Center water Supply Optimization Model Developed By: Peter Meier, Brookhaven National Laboratory Status: Completed. Results exist in Brookhaven National Laboratory report

Description: Developed for Nuclear Regulatory Commission-Department of Energy, New Jersey. Energy Center Study. Classical Lagrange Multiplier Optimization Model.

4. Model: County-Level siting Model

Developed By: Peter Meier, Brookhaven National Laboratory-for National Coal Utilization Assessment

Status: Operational on Brookhaven National Laboratory CDC 7600 for the three power pools of the Northeast Description: Performs a county-level disaggregation of regional (census region) scenarios. Sites all power plants. Includes costs of transportation, electricity, fuels, and transmission. Uses Office of the Bureau of Economic Research Service (OBERS) projections, location of existing facilities, and water resources data from United States Geological Survey (USGS).

5. Model: National Residuals Discharge Inventory Developed By: Consultants to National Research Council Status: Computerized, exists at Brookhaven National Laboratory CDC 7600

Description: An assessment of residuals generation and discharges and of the costs involved in cleaning up or reducing these discharges. Regional disaqqreqation to ASA (aggregated Subarea, or river basin). Examines Biological oxygen Demand (BOD) and Total suspended Solids (TSS). Examined costs of Best Available Technology (BAT) and Best Practicable Technology (BPT) required to clean up these effluents. 
6. Model: Regional Emissions Projections System (REPS) Developed By: Booz-Allen for Environmental Protection Agency Status: Operational on Brookhaven National Laboratory CDC 7600 Description: Using the most recent National Emissions Data Service (NEDS) emissions inventory to establish baseline emission levels, Regional Emissions Projection Systems (REPS) projects emissions production to a selected future year by $A$ ir Quality Control Regions (AQCR). SEAS economic forecasts are used to compute the growth factors. The projected emissions are then adjusted to include the effects of present and future control regulations. Many user options and overrides are available.

7. Model: Wind Rose Model

Developed By: Paul Michael, Brookhaven National Laboratory Status: Under development. (Resides outside NCAES but is being developed at Brookhaven National Laboratory and will be used extensively by NCAES personnel.)

Description: Describes a yearly average concentration of a pollutant from a point source and to 50 miles.

8. Mode1: Long-Range Trajectory Model

Developed By: Ron Meyers, Rick Cederwall, Brookhaven National. Laboratory

Status: Operational on Brookhaven National Laboratory CDC 7600 (Resides outside NCAES but is being developed at Brookhaven Nátional Laboratory and wili be used extensively by INC̈̈ES personnel.)

Description: Traces the pollution from a point source, over time, using actual meterological data in 3 dimensions. Allows 
8. Description (Cont'd):

the tracing of a pollutant from a specific source over large distances, as well as allowing the incorporation of nonlinear chemistry effects.

9. Model: SECPOP

Developed By: Office of Radiation Programs, USEPA

Status: On cards, but has not been used at BNL

Description: Determines the population distribution around any given point in the U.S. using master Enumeration District List from the 1970 census.

10. Model: ESNS-BESOM Interface (EBIP)

Developed By: Walter A. Sevian, S. Michaile, Brookhaven National Laboratory

Status: Operational on Brookhaven National Laboratory CDC 7600 Description: This program takes the aggregated BESOM Intermediate Energy Form (IEF) outputs along with other totals and, after application of suitable assumptions, disaggregates the IEF's, generates an equivalent ESNS trajectory file, and executes the ESNS model. The outputs of the ESNS model are simply the process-by-process emissions generated by the aggregated IEF solutions to the BESOM model.

11. Model: Energy System Simulator (ESS) Developed By: Paula Newhouse, walter A. Sevian, Brookhaven National Laboratory

Status: Operational on Brookhaven National Laboratory CDC 7600 Description: An aggregated activity level version of ESNS that generates energy flows and environmental effects. About 110 processes are included in the network. 
12. Model: R-ESNS

Developed By: Walter A. Sevian, Brookhaven National Laboratory Status: Under development

Description: Regionalized ESNS model to be developed primarily from BEMIS data when completed. This will be the primary vehicle through which BEMIS data will be available.

13. Model: Air Pollution Linear Rollback Model Developed By: Environmental Protection Agency Status: Operational on Broukliaven National Laboratory CDC 7600 Description, A linear adjistment iludel ful estimating urban air quality under various automobile emission control requirements. Health impacts can also be estimated, given a suitable set of assumptions about stationary.emission source growth rates.

\section{Data Bases:}

1. Data Base: Committee on Alternative Energy Strategies (CONAES) Developed By: Being developed at Brookhaven National Laboratory in conjunction with Committee on Alternative Energy strategies Status: Operational on Brookhaven National Laboratory CDC 1600

Description: Environmental information about nuciear and other technologies. This is basically an ESNS input file which includes all of the Teknekron new technology data plus additional nuclear data from a CONAES subgroup. 
2. Data Base: National Emissions Data Service (NEDS) Developed By: Environmental Protection Agency

Status: Developed, undergoes periodic updates. Latest version is available at Brookhaven National Laboratory for use with Regional Emissions Projection System (REPS)

Description: A county-level compilation by Environmental Protection Agency (EPA) of all point sources of air emissions as well as area wide activity and associated air emissions. These data are spotty. Also available as a system 2000 data base from the Atmospheric Sciences Division including additional state and local dates. Quality control checks are being implemented.

3. Data Base: Storage and Retrieval of water Quality and Related Data (STORET)

Developed By: Environmental Protection Agericy Śtatus: Completed, resides on Environmental Protection Agency (EPA) computer, regularly updated and added to Description: Contains data on "water quality, municipal and industrial waste facility inventory, water quality standaras compliance, fish kill, oil spill, construction cost, and other related data."

4. Data Rase: Storagc and Retrieval uf Aerometric Data (SAROAD) Developed By: Environmental Protection Agency 
4. Status: Completed, resides on Environmental Protection Agency computer, regularly updated and added to. Also available at Brookhaven National Laboratory, Atmospheric Sciences Division, as a System 2000 data base

Description: Contains air quality and meterological data and generates air quality data reports.

5. Data Base: Edited Version of Master Enumeration District List with coordinates

Developed By: U.S. Census Bureau

Status: on tape, but has not been used at Brookhaven National Laboratory

Description: The population, longitude, and latitude of the enumeration district population centroid, from the 1970 census.

6. Data Base: Biomedical and Environmental Modeling Information System (BEMIS)

Developed By: Bruuklıaven National Laboratory and Teknekron, Incorporated

Slalús: Under dovelopment

Description: A critical review of the environment cocfficientg in the current Brookhaven National Laboratory Energy Model Data Base by. Teknekron, Incorporated, with a goal to their reformulation for use in health impact assessment, has resulted in a decision to develop BEMIS. With a revised set of both coefficients and process representation, the BEMIS structure will be used to develop a regional version of ESNS, R-ESNS.

7. Data Base : County Level Data Bank of Future Energy Supply Facilities

Developed By: Walter A. Sevian, Salvador R. Bozzo, Brookhaven, National Laboratory 
7. Status: Operational on Brookhaven National Laboratory CDC 76.00 Description: This data bank contains all future energy supply facilities to the year 1985 and beyond in some cases. The entries are keyed to the process classifications in the ESNS model, and it is planned to interface this data bank with the ESNS model to meaningfuily assign future energy scenario emissions in space.

8. Data Base: Business Patterns Data Bank Developed BY: walter A. Sevian, Regina.Hakoopian, Brookhaven National Laboratory

Status: Under development

Description: County level clusters of industrial facilities will be developed into an information file to be used with the MEDABA medical data base and the ESNS model: This base year will be 1970 and site-specific projections will be accepted.

9. Data Base: WATSTORE Developed BY: U.S. Geological Survey Status: Completed, resides on USGS computer, regularly updated and added to

Description: Hydrologic information on surface and subsurface waters.

10. Data Base: County Level water File Developed By: E. Kaplan, Brookhaven National Laboratory Status: water quality file completed, hydrologic file under development

Description: water quality and hyarologic data aggregated at the county and river basin level. Data extracted from EPA, USGS, and other agencies. 
11. Data Base: Disaggregated Emission Coefficients in the Commercial/Residential, Industrial, Electric.Utility, and Transportation Sectors

Developed By: · P.s Raskin, R. Rosen, Energy Systems Research, Incorporated

Status: Completed, noncomputerized, report to be published Description: In the electrical sector, emission coefficients were disaggregated to account for variations in fuel mix (coal, gas, oil...) and $\mathrm{mix}$ of old and new plants. In the industrial sector, emission coefficients are disaggregated for the five major energy consuming industries plus "others.". These coefficients were specific to the industry, fuel, process, and age of plants in service. In the commercial/residential sector, emission coefficients are disaggregated by fuel type. (oil, gas...) and end use (space heat, water heat, and cooling). In the transportation sector, emissions were calculated only for automobiles. The emission coefficients for the transportation sector are disaggregated by model year.

12. Data Base: Emissions Data Base using FPC Form 67 Developed By: Federal Power Commission

Status: Air data variable at Brookhaven National Laboratory in system $2 \mathrm{~K}$ data base water data available at Brookhaven National Laboratory on tape

Description: Air quality control data for steam electric power plants 
MATERIALS

Data Bases:

1. Data Base: . Reference Materials System

Developed By: Brookhaven National Laboratory.

Status: Complete, BNL 50609, not computerized

Description: Information regarding materials requirements for various processes, e.g., resource extraction, processing, transportation, etc.

INTERNATIONAL

Models:

1. Model: MARKAL-IEA Market Allocation Model

Developed By: Brookhaven National Laboratory (International Energy Agency), Kernforschungsanlage (KFA) Germany

Status: Under development

Description: A synthesis of DESOM and the KFA model designed. to be nation independent and to perform analysis. on alternative R\&D strategies and resource sharing among IEA countries. This is a time phase LP model.

2. Model: WASP, Electric Generation Capacity Expansion Model Developed By: International Atomic Energy Agency Status: Operational on Brookhaven National Laboratory CDC 7600 Description: A group of six interrelated computex code modules developed to meet the needs of electric generation capacity expansion in developing countries. WASP accepts data on the 
2. Description (Cont'd):

load characteristics, annual peak demand for each year in the study, and a description of the fixed system. It can consider up to 20 candidate expansion plants. Within user generated constraints, WASP considers all acceptable expansion configurations and carries out a dynamic optimization of alternative expansion plans.

\section{Data Dases :}

1. Data Base: Developing Countries Data Base Developed By: Brookhaven National Laboratory - LDC Program Status: Under development, partly computerized Description: Energy production and import data for LDC's as group. More detailed energy and economic data for twelve selected countries, enough to create a Reference Energy System (RES). Detailed technological data for irrigation, using renewable resources (especially biogas).

2. Data Base: International Energy Agency, ESNS Input File Develnped By: Brookhaven National Laboratory Status: Operational on Brookhaven National Laboratory CDC 7600 Description: A collection of energy, economic, and environmental data for each International Energy Agency (IEA) participating country, as well as for cross-country technology characterization. The Energy Systems Network Simulator (ESNS) program and its associated interactive program have been adapted to interface with the IEA data base. Units are metric. Energy supply and demand data for each country are stored using APL format so that tabular information for reports is generated quickly and easily. 
3. Data Base: IEA Data Base for MARKAL

Developed By: Brookhaven National Laboratory

Status: Planning

Description: All data for MARKAI

POPULATION AND HEALTH

Models :

1. Model: Population Projections by County Developed By: Brookhaven National Laboratory

Status: Undex development (working paper \# 2)

Description: Uses natural rate of increase method with 19501970 rates and 1960-1970 rates. Also, a ratio method, a trend method, and a fired rate method. Coded by Federal Information Processing Standard (FIPS) - 1970 and by Inter-Censal Equivalent Area Code (ICEAC).

2. Model: Health Impacts Simulation Model

Developed By: S. Morris, Brookhaven National Laboratory; and Granger Morgan

Status: Under development

Description: A simulation model which uses a probabilistic approach to study health impacts of air pollution from coalfired power plants. Two versions exist: in one, each parametric is represented by a probability density function while in the other, the mean of the pdf is used. Uses Paul Michael's Wind Rose Model as a base.

3. Model: Interactions Between Income; Pollution, Mortality, Sex, Age, and Race 
3. Developed By: Salvador Bozzo, Brookhaven National Laboratory Status: Completed and operative

Description: The model uses the Medical Data Bank (MEDABA) files to compose groups of countries which contain enough population to reflect the impact of different levels of pollution and income in the population. E.g.. compose a group of one million persons living in low income, high pollutant area and contrast with similar groups living in low income low pollutant areas. Examines mortality data with respect to demographic characteristics

Software to group countries and compute disease-specific mortality rates for each of the groups is operative. This output can bc coupled to a graphics package on the DTC 300/s terminal.

4. Model: Comprehensive Model Relating Energy, Environment, Humans, and Economics

Developed By: Salvador Bozzo, Brookhaven National Laboratory Status: Under development

Description: The interrelationships among energy, environment, human health, and economics are described by the following chain:

\section{$R \dot{E} \mathrm{D}$}

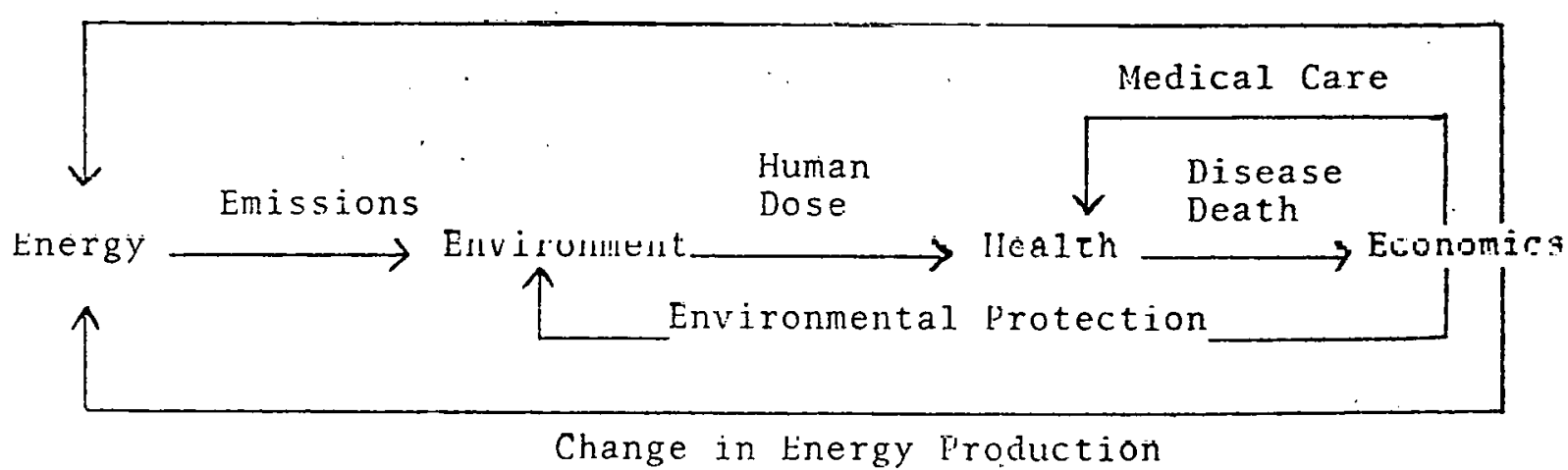


4. Description (Cont'd):

An attempt to describe the transfer functions between the different segments of the model is being carried out. Input data are from the Medical Data Bank (MEDABA).

5. Model: CEM Accident Model

Developed By: The Center for Environment, and Man, Incorporated, for Department of Transportation

Status: Operational on Brookhaven National Laboratory CDC 7600 Description: Estimates future auto occupant deaths in relative and absolute terms, using algorithms based on historical data which describes how the frequency and number of auto occupant deaths changes with alteration in the number of auto registrations (fleet size), and an accident trend model describing how auto occupant deaths change in relation to variations in the mix of small and large cars (fleet mix).

6. Model: Population Dynamic Model

Developed By: S. Bozzo, K. Novak, Brookhaven National Laboratory Status: Operational on Brookhaven National Laboratory CDC 7600 Description: Using 1970 census data, 1970 fertility data, 1967-1971 mortality data, and county level net migration data between 1960-70, the interrelated effects of median family income and $\mathrm{SO}_{\mathrm{x}}$ emissions on county level population dynamics was examined. Age, race, sex-specific results are produced. Modifications and improvements to the model and input data are under way.

7. Model: Mortality Effects Model Developed By: S. Bozzo, K. Novak, Brookhaven National Laboratory 
7. Status: Operational on Brookhaven National Laboratory CDC 7600 Description: Using a linear combination of diseases, the effects of $\mathrm{SO}_{\mathrm{x}}$ emissions and median family income on total mortality and specific causes of death can be computed. Age, race, sex-specific results are produced. Modifications and improvements to the model and input data are under way.

8. Model: Health Impacts Program Developed By: J, Nagy, Brookhaven National Laboratory Status: Under development .

Description: Integrates health impacts with energy networks by associating health impact coefficients in the correct units with each process in the network. The impacts of each process are calculated and these can be aggregated to any level or by any criteria desired. Deaths, injuries, and illnesses are considered. Uncertainty is accounted for by providing best estimate and upper and lower range of estimate.

\section{Data Bases:}

1. Data Base: Medical Data Bank (MEDABĀ) Developed BY: . Salvador Bozzo, Brookhaven National Laboratory Status: Completed, computerized

Description: Part A: County-level Data. Each county includes Federal Information Processing standard (FIPS) code, Standard Metropolitan Statistical Area (SMSA) code, State Economic Area (SEA) code, and National Center for Health Statistics (NCHS) code. Geographic characteristics, center of population, complete demographic characteristics by age, sex, and race, complete migration chacteristics by age, sex, and race, natality 
1. Description (Cont'd):

data (1960-1970), quality of life data, energy use data, emission data. Part B: Three magnetic tapes-sequential hierarchical file with six million records. Mortality data by age, sex, race by 1969-1971. 


\author{
APPENDIX C \\ PUBLICATIONS LIST \\ January 1, 1977 - March 31, 1977 \\ Energy Programs \\ Department of Applied Science \\ Brookhaven National Laboratory \\ Upton, New York 11973
}

\title{
I. Energy Systems Analysis
}

BNL 20916

BNL 21545

BNL 21572

BNL 21667

BNL 21823

(Pt. 1 or 2)

BNL 21839

BNL 21854

BNL 21874
Meier, Peter M.. McCoy, T. H. An Analytical Approach to the Determination of Urban Population Density Gradients and its Application to Energy Planning Problems. October, 1976.

Goldberg, Murrey D., Sevian, W., Reisman, A., Newhouse, P. Energy Model Data Base Program. June, 1976.

Goldberg, Murrey D. Data Needs for Energy Policy Assessment (prepared for Conference). June, 1976.

Behling, D. J. A Dynamic Systems Analysis of the Relation Between Energy and the Economy. July, 1976.

Haynes, Virgil O.. Jordan, Robert K., Marmor, Michael, Sajlor, Vance L., Shore, Ferdinance J., Steinberg, Meyer. Balanced Program Planning for Health \& Environmental Research Conservation \& Energy Efficiency (including waste Utilization) Vols. I \& II. July 15, 1975.

Reisman, Ann W. Access to the Energy system Network Simulator (ESNS). Via Remote Computer Terminals. August 15, 1976.

N̄ewhouse, Paula $\bar{H}$. Energy Data Base Application: Implementing the Energy Model Data Base Uing System 2000. September, 1976.

Falmedo, F. A brief description of The Developing Country Energy Project. Informal Report. October 1, 1976. 
Publications List

Page 2 .

January 1, 1977. - March 31, 1977

I. Energy Systems Analysis

BNL 21920

Marcuse, W., Carhart, S., Mulherkar, S. Residential Energy Demand Analysis Data \& Methodology. October, 1976.

BNL 21954

Morgan, Granger; M.. Morris, Samuel C.

An Approach to Characterizing Uncertainty

in Health Effects Estimates for Coal Fired

Power Plants. October 26, 1976.

BNL 21955

Calef, Charles E. An Environmental Critique of Solar Power by Bioconversion Methods. ! April 6, 1976.

BNL 21958

Bhagat, N. K., Hoffman, K. C. Systems Framework for Materials Policy Analysis. To

be presented at ORSA/TIMS Meeting, San Francisco, California, May 1977.

BNL 21995

Shaw, M. I., Wood, R. K. Volumes and Transportation Costs of Fossil Fuels Shipped Between Census Regions.

BNL 22045-A

Goettle, R. J., Cherniavsky, E. A., and Tessmer, R. G. An Integrated Multi-Regional Energy and Interindustry Model of the United States. To be presented Spring. 1977.

BNL 22153

Meier,. P. M., McCoy, T. H. Analytical Determination of Urban Population Density Gradients.

BNL 22280-A

Davitian, H. The use of Wind Power by Electric Utilities. January 19, 1977.

BNL 22282

Van Horn, Andrew J., Wilson, Richard. BEAG The Status of Risk-Benefit Analysis. Informal Report. December, 1976.

BNL 22283

Chang, Benjamin, Wilson, Richard. BEAG Mitigation of the Effects of Sulfur Pollution. Informal Report. July 5, 1977.

$\bar{A}=A b s t r a c t$ 
Publications List

Page 3.

January 1, 1977 - March 31, 1977

I. Energy Systems Analysis

BNL 22311

BNL 22318

BNL 22385

BNL 22416-A

BNL 22461-A

BNL 22529

BNL 22530

BNL 22557

BNL 50500

BNL 50501

BNL 50511

$A=$ Abstract
Palmedo, P. F. The Role of Renewable Energy Technologies in Developing Countries. Informal Report. January 10, 1977.

Cecil, J. I., Morell, D. New Jersey's Natural Gas Shortage: A Policy Analysis. December, 1976.

Palmedo, P. F. Energy Technology Assessment: Considerations of Geographical Scale. January 15, 1977.

Meier, P. M. Regional Science and Energy Policy: A Methodology for the Assessment of Coal Utilization in the Northeast.

Meier, Peter M. A Linear Programming Approach to County Level Energy Scenario Disaggregation.

Morris, S. C., Morgan, M. G. Relation of Outdoor Carbon Monoxide to Carboxyhemoglobin Levels.

Morgan, M. G., Morris, S. C. Needed: A National $R \& D$ Effort to Develop Individual Air pollution Monitor Instrumentation.

Bozzo, S. R., Galdos, F., Hakoopian, R. Interactive Plotting Package Using the $6600 \mathrm{CDC}$ and DTC 300/s Terminal. Informal Report. March, 1.977.

Behling, D. Dullien, R. Hudson, E. The Relationship of Energy Growth to. Economic Crowth Under Alternative Energy Policies.' March, 1976.

Drysdale, Frank R. Calef, Charles E. The Energetics of the United States of America: An Atlas. september, 1976.

Reisman, A. W., Goldberg, M. D. Fuel-Specific Environmental Emissions for Industrial Processes. January, 1976. 
'ublications List

r'age 4 .

January 1, 1977 - March 31, 1977

I. Energy Systems Analysis

BNL 50532

Lukachinski, J., Tessmer, R. 1985 Technical Coefficients for Inputs to Energy Technologies. June, 1976.

BNL 50537

Tessmer, R. J., Abilock, H., Bodin, L., Indusi, J., Marcuse, W., Nathans, R., Sanborn, Y. A Study To Assess The Application of Shadow Pricing Techniques to National Energy Resource Planning. JuIy, 1976.

BNL 50538

Lukachinski, J., Tessmer, R. G. Economy-Wide Impacts of Interfuel Substitution: Substitution of Electricity for Imported Oil. June, 1976.

BNL 50550

Brainard, J., Davitian, H., Goettle, R., Palmedo, P. A Perspective on the Energy Future of the Northeast United States. June, 1976.

BNL 50552

Lee, John. Future Residential and Commercial Energy Demand in the Northeast. March, 1976.

BNL 50561

Meier, Peter M., Morell, David. Issues in Clustered Nuclear Siting: A Comparison of a Hypothetical Nuclear Energy Center in New Jersey with Dispersed Nuclear Siting. September, 1976.

BNL 50562

Isard, walter, Reiner, Thomas, Van Zele, Roger, Stratham, James, et al Regional Economic Impacts of Nuclear Power Plants. August, 1976.

BNL 50563

Meier, Peter M. Optimization of water Conveyance. September, 1976.

BNL 50567

Church, Richard L., Cohon, Jared L. Multiobjective Location Analysis of Regional Energy Facility Siting Problems. October, 1976.

BNL 50580

Brainard, J., Munson, J. S. Palmedo, P. F. The Energy Situation in New England. November, 1976. 
Publications List

Page 5 .

January 1, 1977 - March 31, 1977

I. Energy Systems Analysis

BNL 50581

Muench, Thomas J., Wooders, Myrna, H., McLean, Richard. Report on the Regional and System Type Disaggregation of the Single Family Dwelling. Space Heat Energy Demand Sector. August, 1976.

BNL 50604

Behling, David J., Jr. The Impact of Alternative Nuclear Moratorium Legislation on the U. $S$. Economy. December, 1976.

BNL 50608

Tessmer, Raymond G., Jr. Input-output Capital Coefficients for Energy Technologies. December, 1976 .

BNL 50609

Bhagat, N. Reference, Material Systems: A Sourcebook for Material Assessment. December, 1976.

BNL 50614

Daikuku, Richard. Residential space Heating and Cooling in New England 1972-2000. December, 1976.

BNL 50641

IEA - An Initial Multi-National Study of Future Energy Systems and Impacts of Some Evolving Technologies: March 25, 1977.

II. Energy Technology

BNL 21636

Benenati, R., Powell, J., Lazareth, O. W. High wall Load, Low Activity Blankets for Fusion Power Reactors. July 14, 1976.

BNL 21876-A

Beardsworth, E., Powell, J. R. Assessment of Long Range Projects--Anticipating the Tmplementatinn of Fusion. Submitted for AAAS Annual Meeting in Denver (20-25 February 1977).

BNL 22027

Gottesfeld, S., Srinivasan, S. Electrochemical and Optical Studies of Thick Oxide Layers on Iridium and Their Electrocatalytic Activities for the oxygen Evolution Reaction. Electroanalytical and Interfacial Electrochemistry (to be published in)

$A=$ Abstract 
Publications List

Page 6

January 1, 1977 - March 31, 1977

II. Energy Technology

BNL 22081-A

BNL 22086

BNL 22120-A

BNL 22157

BNL 22158

BNL 22275

BNL 22315

$A=$ Abstract
Beaufrere, Yeo, R. S., Srinivasan, S. The Hydrogen-Halogen Energy Storage System for Electric Utility Applications (A) 12th Intersociety Energy Conversion Engineering Conference, Washington, D. C. August 28,September 2, 1977.

Isaacs, H. S., Russel1, P. G. Electrochemical Characteristics of $\mathrm{ZrO}_{2}-\mathrm{Y}_{2} \mathrm{O}_{3}$ solid Electrolytes for Fuel Cells (A) 15Ist Meeting of the Electrochemical Society, Phil. Pa.. May 8-13, 1977.

Lu, P. W. T, Srinivasan, S. ElectrochemicalEllipsometric studies of oxide Films formed on Nickel during oxygen Evolution (a) lslst Meeting of the Electrochemical Society, Phil. Pa. May $8-13,1977$.

Risse11, P. G., Kovac, N., Srinivasan, S., Steinberg, M. The Electrochemical Reduction of Carbon Dioxide, Formic Acid, and Formaldehyde. To be published in the $J$. of the Electrochemical Society, 1977.

Salzano, Frank J. Hydrogen Technology Development Program at the Brookhaven National Laboratory. Part of the Proceedings - ERDA Contractor's Review Meeting on November 8 \& 9, 1976. Airlio, VA.

Lu, P. W. T., Srinivasan, S. Nickel Based Alloys as Electrocatalysts for oxygen Evolution from Alkaline Solutions. Informal Report. January, 1977.

Botts, T. E., Powell, J. R. Waste Maragement Procedures for CTR Central Power stations. Conference. June 12-17, 1977. 
Publications List

page 7.

January 1, 1977 - March 31, 1977

II. Energy Technology

BNL 22316

BNL 22317

BNI, 22388

BNL 22389

BNL 22390

BNL 22391

BNL 22392

BNL 22393

$B N L-22394$

BNL 22395
Powell, J. R. The Safety of Large Fusion Magnet Systems. Meeting - June 12, 17, 1977.

Hsieh, S. Y., Lehner, J., Powell, J. A conceptual Demountable TF Magnet Design for UWMAK-II Fusion Reactor. American Nuclear Snciety 1977 Annual. Meeting. June 12-17. 1977.

Fillo, J. A. Powell, J. R. Yu, W. S. Coupled Conduction-Turbulent Convection in a Circular Tube. Conference - August 7 - 11, 1978.

Fillo, J.A., Benenati, R., Powell, J. R. Coupled Thermal Radiation - Conduction Analysis. Conference, August 7-1I, 1978.

Hsieh, S. Y., Powell, J. R., Lehner, J. MAXAMAK and MULTIMAK: New Approaches for Tokamak Power Reactors. 1977 Annual ANs Meeting - June 12-17, 1977.

Powell, James, Yu, W. S., Laxareth, Otto. Conduction Cooled Minimum Activity Blankets for TNS ànd EPR Fusion Reartors* Conferense, Junn 12-17, 1977 .

Fillo, J., Majumdar, D., Makowitz, H. Fusion Blanket First Wall Time Dependent Thermal Stress Model. 1977 Annual ANS Meeting June 12-17, 1977.

Powell, J., Lazarcth, O., Fillo, J. $\Lambda$ Liquid Wall Boiler and Moderator (BAM) for Heavy IonPellet Fusion Reactors. ANS Annual Mecting June 12-17, 1977 .

Fillo, John A., Powell James R., Lazareth, Otto. Catalyzed D-D and D-He $e^{3}$ Fusion Blanket Designs. January $24,1977$.

Beardsworth, E. Powell, J. R. The Potential Need for Fusion in The U. S. Energy System. ASN Annua? Meeting - June 12-17, 1977. 
ublications List

zge 8 .

January 1, 1977 - March 31, 1977

II. Energy Technology

BNL 22396

Fillo, J.A., Powell, J. R.. Lazareth, O. Thermal Hydraulic and. Neutronics Analysis of a SAP-Thermosyphone Blanket* ANS Annual Meeting - June 12-17, 1977.

BNL 22443

Goldstein, M. Barker, J. J., Gangwer, T. A Photochemical Technique for Reduction of Uranium and Subsequently Plutonium in the Purex Process. September, 1976.

BNL 22460

Fillo, J. A. Heat Transfer Models for Fusion Blanket First Walls. February 18, 1977.

BNL, 22497

Hsieh, S. Y., Powell, J., Lehner, J. Cryogenic Aspects of A Demountable Toroidal Field Magnet System for Tokamak Type Fusion Reactors. Submitted to 1977 Cryogenic Engineering. Conference August 2-5, 1977.

BNL 22559

Karkheck, J. Powell, J. Prospects for the Utilization of waste Heat in Large Scale District Heating Systems. March, 1977.

BNL 50576

Batey, John, Gazerro, Vincent, Salzano, F. J., Berlad, A. L. Energy Management in Residential and Small Commercial Buildings - Annual Report 1976. July, 1976.

BNL 50586

Berlad, A. L., Galzano, F. J., Batey, J. Energy Transport Control in Window Systems. September 15. 1976.

BNL 50590

Salzano, Frank J., Editor. Hydrogen, Storage and Production in Utility Systems - Semi-Annual

progress Report. July 1, 1975 to December 31, 1975.

IIT. Engineering Analysis

BNL-NUREG

22419
Reich. M., Esztergar, E. Technical Coordination of Structural Integrity status-Progress Report. February, 1577 . 
Publications List

Page 9

January 1, 1977 - March 31, 1977

III. Engineering Analysis

BNL 22462

Fillo, J. A., Powell, J., Ye, W. S. Thermal Hydraulic Analysis of Low Activity Fusion

Blanket Designs. February 22, 1977. 


\author{
PUBLICATIONS LIST \\ April 1, 1977 - June 30, 1977 \\ Energy Programs \\ Department of Applied Science \\ Brookhaven National Laboratory \\ Upton, New York 11973
}

\title{
I. Energy Systems Analysis
}

BNL 20133

BNL 20323

BNL 20435

BNL 20664

BNL 20979

BNL 21918

BINL 22623

BNL 22676

BNL 22677
Jones, H. G., DeJong, J., Bronheim, H., and Nathans, R. An Analysis of the 1973-74 Energy Shortage in the New York City Region.

Rubin, E.S., Edelston, B. B., Gunwaldsen, D. S., and Notary, K. E. The Pennsylvania Energy System.

Meier, P. M. Energy Facility Location: A Regional Viewpoint.

Meier, P. M. Preliminary Assessment of a Hypothetical Nuclear Energy Center in New Jersey-Supplement

Sevian, W. A. The Energy System Network Simulator (ESNS) II. A User's Guide,. September 1975.

Brainard, J. P., Munson, J. S., and Palmedo, P. F. A Briefing Brook on the Energy Situation in New England.

Allanturk, I. . Tee, J., and.Goldstein, G. The Impact of Load Management on Consolidated Edison Company's Generation.

Palmedo, P. F. Integrated Environmental Analysis and the Development of New Energy Technologies. Subcommittee: on the Environment and the Atmosphere of the Committee on Science and Technology, U.S. House of Representatives, March 1, 1977.

Carroll, T. O., Allentuck, J., Goldberg, M. D., Nathans, R., Palmedo, P. F., Pouder, R., and Svei, D. An Energy. Information and Analytic System for New York State. 
Publicationș List

page 2

April 1 - June 3i), 1977

I. Energy Systems Ana lysi.s

BNL 22730

Behling, D. J., Cherniavsky, E. A., and Bojenan, K. C. Overview of Technologizal-Economic Models for Energy Policy Analysis. Workshop on Energy Strategies, International Institute for Applied Systems Analysis, Laxenburg, Austria, May 18, 1977.

BNL 22814

Hermelee, A. Regional Reference Erorgy Systems. Topical Report, National Center for Analysis of Exergy Systems.

BNL 22284

Vaniorn, A. J., And wilson, R. BEAG - Liquified Natural Gas: Safety Issues, Public Concerns, and Decision Making.

BNL 22499

Stern, R., Brainard, J., Goldstein, G., Palmedo, P., and Reisman, A. Erivironmental Residuals for Use in the Evaluation of State Energy Conservation Programs.

BNL 22678

Meier, P. M. Sociopolitica]. Ramifications of Nuclear Energy Centers: American Nuclear Society Executj.ve Seminar oir Nuclear Energy Centers, Arlington, Virginia, April 26, 1977.

BNL 22367

Hofman, K. C., and Jorgenson, D. (Harvard Univ). Tecinological-Economic Models Eor Strategic Planning. Submitted for Special Session on Energy Systoms Modeling, 7 th Triennial World Cungress of the International Federation of Automatic Control, Helsinki, June 12-16, 1977.

BNL 22913

Meier, P. M. A Regional Analysis of the Use of Urban Refuse as an Energy Source in the Northeast. Northeast Regional Science Review.

BNL 22928

Meier, A. K. Intermediate Transport in Southeast Asia, June 1977 .

BNL 50465 Meier, P. M., and Palmedo, P. F., et al. Preliminary Assessment of a Hypothetical Nuclear Energy Center in New Jersey. 
Publications Iist

Page 3

Ap:il 1 - June 30, 1977

I. Energy Systems Analysis

BNL 50500

Behling, D. J., Dullien, R., and Hudson, E. The Relationship of Energy Growth to Economic Growth Under Alternative Energy Policies, March 1976.

BNL 50541

Tessmer, R. G., Behling, D. J.' The Effects. of Alternative Oil Stockpile Programs on the U.S. Economy 1976-1979. Final Results. Final Results, June 1976. Prepared for the office of the Assistant Administrator for International Affairs.

BNL 50551 .

Sailor, V., and Shore, F. J. The Future of Nuclear Power in the Northeast.

BNI 50552

Lee, J. Future Residential and Commercial Energy Demand in the Northeast.

BNL 50554

Transportation Energy Consumption and Conservation Policy Options in the Northeast. Systems Design Concepts, Inc.

BNL 50560

Edelston, B.'S.', and Rubin, E. A. Current and Future Use of Coal in the Northeast.

BNL 50566

Backstrom, T. D., and Baram, M. Artificial Islands for Cluster-Siting of the Offshore Energy Facilities: An Assessment of the Legal and Regulatory Framework.

BNL, 50581

Muench, T. J., Wooders; M., and McLean, R.

Report on the Regional and System Type Disaggregation of the Single Family Dwelling, Space Heat Energy Demand Sector. August 1976.

BNL 50609

Bhagat, N. Reference Material Systems: A Sourcebook for Material Assessment. December. 1976.

BNL 50637

Morgan, M. G., and Morris, S. C. Individual Air Pollution Monitors; 2 : Examination of Some NonOccupational Research and Regulatory Uses and Needs. January 1977. 
Publications Iist

Page 4

April 1 - June 30, 1977

I. Energy Systems Analysis

BNL 50641 Brookhaven National Laboratory. An Initial Multi-National Study of Future Energy Systems and Impacts of Some Evolving Technologies. Kernforschungsanlage, Julich.

II. Energy Technology

BNL 21119

Brain, C., Gängwer, T., and Goldstein, M. Partitioning of Aulinilie tilements trom High Level Radioactive Waste Using Laser Photochemical Methods. American Nuclear Society 1976 Annual Meating, Toronto, Ontarie Cáldald, June 13-18, 1976 .

BNL 21165

Salzano, F. J., and Srinivasan, s. Proceedings of the First International Energy Agency Water Electrolys is Workshop.

BNL 21636

Benenati, R., Powell, J., and Lazareth, O.W. High wall Load, Low Activity Blankets for Fusion Power Reactors. Submitted to 1976 ANS Mepting, Washington, D.C., November 15-19, 1976.

BNL 22157R

Russell, P. G., Kovac, N., Srinivasan, S., and Steinberg, $M$. The Electrochemical Reduction of Carbon Dioxide, Formic Acid, and Formaldehyde.

BNL 22594

Powell, J., Hsieh, S. Y., and Lehner, J. The Deals Magnet Concept: Applications and Development. Informal Report.

BNL 22654

Lu, P. W. T.. and Srinivasan, S. Nickel Based Alloys as Electrocatalysts for oxygen Evolution from Alkaline Solutions.

BNL 22656R

Goldstein, M. Low Proliferation Risk Breeder Reactor Fuel Cycles.

BNL. 22667

Powe11, J. R., Hsich, S. Y., Lehners, J., Reich, M., Danby, G., and Prodell, A. Safety and Reliability Aspects of Superconducting Magnets for Thermonuclear Power Reactiors. 
Publications Iist

Page 5

April 1 - June 30, 1977

II. Energy Technology

BNL 22698 Reich, M., Lehner, J., and Powell, J. Structural Aspects of Superconducting Fusion Magnets.

BNL 22724

Goldstéin, M., Barker, J. J., and Gangwer, T. Photochemistry in Nuclear Fuel Reprocessing, April 1977.

BNL-NUREG 22736 Isaacs, H. S. The Kinetic Dependence of Iron Catalyzed Graphite Oxidation of Oxygen Potential. Thirteenth Biennial Conference on Carbon, Irvine, California, July 18-22, 1977.

BNL 22758,

Botts, T. E., and Powell, J. R. Waste Management Considerations for Fusion Power Reactors.

BNL 22776

Yeo, R. S., and Srinivasan, S. An Evaluation of the Electrochemically Regenerative HydrogenChlorine Cell for Energy Storage. Electrochemical Society Meeting, Atlanta, Georgia, October 9-14, 1977.

BNL 22793

Isaacs, H. S., and Olmer, L. J. An AC Technique for Characterizing Solid Oxide Fuel Cells (Extended Abstract). Workshop on High Temperature Solid, Oxide Fuel Cells, BNL, May 5-6, 1977.

BNL 22820

Beaufrere, A., Yeo, R. S., and Srinivasan, S. The Hydrogen-Halogen Energy storage systein for Electric Utility Applications. 12th Intersociety Energy Conversion Engineering Conference, Washington, D.C., August 28 - September 2, 1977.

BNL 22821

Lehner, J., Reich, M., and Powell, J. Three Dimensional Inelastic Evaluation of a Controlled MFE (Magnetic Fusion Energy) Reactor Magnet. To be presented at the 4 th International Conference on "Structural Mechanics in Reactor Technology" San Francisco, California, August 15-19, 1977. 
Publications iist

Page 6

April 1 - June 30, 1977

II. Energy Technology

BNL 22825 Srinivasan, S., Olender, H., Miles, M. H., Davidson, C. R., Tseung, A. C. C., and Isaacs, H. S. Electrocatalysis of the oxygen Electrode Reaction in Acid, Alkaline and Buffered Electrolytes.

BNL 22826

Fillo, J. A. Heat Transfer Models for Fusion Blanket First Walls. Submitted to 14th Annual Meeting of the Society of Engineering Science, Lehigh University, November 14-16, 1977.

BNL 22853A Goldstein, M., Anderson, R., Gangwer, T., Selvaduray, G., Braun, C., Sevian, W., and Lester, R. Waste Management and Proliferation: An Assessment of Technologies and Policies Relevant to Nuclear Power.

BNL 22877

Isaacs, H., Russell, P., Tseung, A., and Srinivasan, S. Solid Oxide Fuel Cells: Electrode Kinetics and Interconnection Materials.

BNL 22956

Powell, J. R. Reactor Technology--Power Conversion systems and Reactor operation and Majntenunce. EPRI Revfew Meeting on Advanced ruel Fusion, Chicago, June 27-28, 1977.

BNL 22978 Botts, T., Majumdar, D., Powell, J., Frunkin, B., DeMund, T., and Wolf, H. Availability of Fusion Power Plants. ANS winter Meeting, San Francisco, November 27 - December 2, 1977.

BNL 23035

Berlad, A. Full Efficiency Zone Heating, June 1977.

BNL 50616

Powell, J., Hsieh, D., and Lehner, J. DEALS: A Demountable Externally Anchored Low Stress Superconduction Magnet System for Fusion Reactors.

BNL 50628

Goldstein, M., Gangwer, T., Braun, C., and Lester, R. Technology Assessment and Impact Analysis of Separation Methods Applied to Radioactive Waste Management. 
Publications Iist

Page 7

April 1 - June 30, 1977

II. Energy Technology

BNL 50647 Berlad, A. L., Lin, H. C., Batey, J., Salzano, F. J., Yu, W. S., Hoppe, R. J., and Allen, T. Seasonal Performance and Energy Costs of Oil or Gas-Fired Boilers and Furnaces. March 1977.

III. Engineering Analysis

BNL-NUREG 22648 Bezler, P., and Curreri, J. R. Effect of Damping on the Response of a Non-Linear System with Multiple Sine wave Excitation. 4th International Conf. on Structural Mechanics, CA, August 15-19, 1977.

BNL 22649

Bezler, P., and Curreri, J. R. Subharmonic Excitation in an HTGR Core. 4th International SMIRT, San Francisco, California, August 15-19, 1977 .

BNL-NUREG 22650 Bezler, P., Curreri, J., and Koplik, B. OSCIL and OSCVERT: Computer Codes to Evaluate the Non-Linear Siesmic Response of an HTGR Core.

BNL-NUREG 2265.i Reich; M., and Koplik, B. Effect of Clearance and Distribution of Mass on the Dynamic Response of an HTGR Core. 4th International SMIRT, San Francisco, California, August 15-19, 1977.

BNL 22652 Reich, M., Prachuktam, S., and Gardner, D. Inelastic Analysis of Finite Length and Depth Cracked Tubes. 4th International SMIRT, San Francisco, California, August 15-19, 1977.

BNL 50589

Ross, M. J.: Strickland, G. $;$ and Milau, J. S. Pressure Drop--Fluid Flow Correlation for Fixed Beds of Small Irregularly Shaped Particles. 


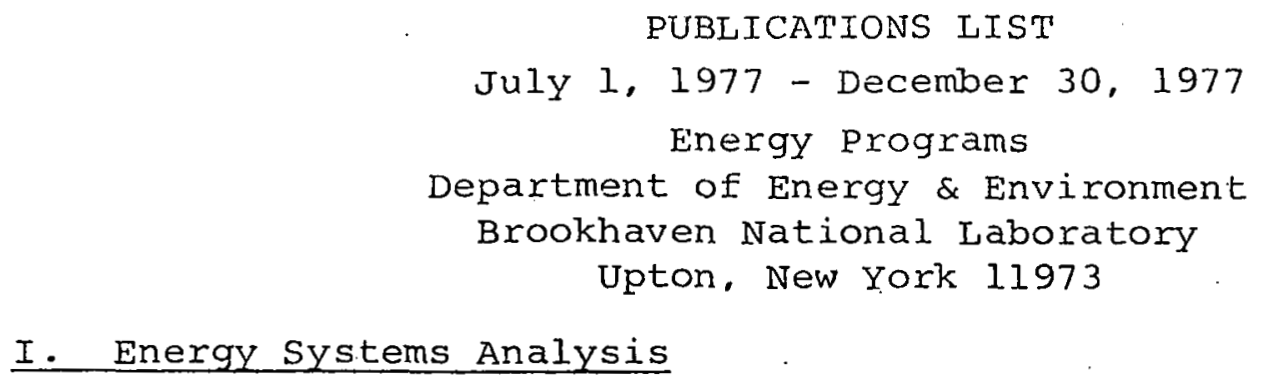

BNL 22279

BNL 22285

BNL 22338

BNL 22728

BNL 22792

BNL 22806

BNL 22895

BNL 22969

BNL 23008
Serwer, D. P. The Rise of Radiation protection: Science, Medicine and Technology in Society, 18961935. Informal Report.

Clark, E. M., Van Horn, A. J. Risk-Benefit Analysis and Public Policy: A Bibliography. November 1976 Informal Report.

Bhas1n, I., Brainard, J., Goettle, R. A Regional Disaggregation of ERDA's Forecast 2 Energy Scenario for the Year 2000. July 1977.

Cherniavksy, E. A., Goettle, R. J., and Tessmer, R. G. An Integrated Multi-Regional Energy and Interindustry Model of the United States. San Francisco TIMS/ORSA Joint National Mtg. May 8-11, 1977.

Meier, P. Regional Science and Energy Policy: A Methodology for the Assessment of Coal Utilization in the Northeast. Prepared for presentation at the 7.th Northeast Regional Science Meetinq. Halifax, N.S. May 28-30, 1977.

Baram, M., Munson, S., and Spencer, J. The Economic Feasibility of Artificial Islands for cluster-Siting of Offshorc Encrgy Facilities. April 1977.

Hoffman, K. C. and Jorgenson, D. W. Fconomir and Technological Models for Evaluation of Energy Policy. U.S. - U.S.S.R. Conference on Mathematical-Eronomis Models, Moscow, U.S.S.R, June 16-18. 1976.

Palmedo, P. F. Energy Systems Analysis and Development. Prepared for the Workshop on Systems Development in Korca, July 12-15, 1977.

Allentuck, J.. and Antoine, J. Electric Energy Production Costs and Consumer Prices in New York State. 
NL 23028

BNL 23028

IAES-CN-36/448

BNL 23082

BNL 23085

BNL' 23087

BNL 23101

BNL 23183

BNL 23193

BNL 23194

BNL 23312

BNL 23340
Hamilton, L. D., and Manne, A. S. Health and Economic Costs of A.lternative Energy Sources.

Hamilton, L. D., and Manne, A. S. Health and Economic Costs of Alternative Energy Sources. International Conference on Nuclear Power and its Fuel Cycle, Salzburg, Austria May 2-13, 1977.

Anderson, R., Goldstein, M., and Selvaduray, G. · Survey of Reprocessing:Technologies. June 1976.

Hoffman, K. C. and Wood, D. O. Energy System Modeling and Forecasting. Annual Review of Energy, Volume $1,1976$.

Behling, D. J., Cherniavsky, E. A. and Hoffman, K. C. Technical-Economic Modeling in Energy Planning. Alternative Energy Sources Symposium, Miami Beach, Florida, December 5, 1977.

Doernberg, A. Energy Use in Japan and the United States. Conference:- Resources for the Future, Washington, D. C. ; September 15, 16, 1977 .

Goldstein; M. Low Proliferation Risk Breeder Reactor Fuel"Cycle. Submitted to: Alternative Energy Sources: A National Symposium, December 5-7, 1977.

Hoffman, K. C. Future Patterns of Energy Utilization Presented at the Energy Workshop of the National Science Council of Ireland, September 13, 197.

Hoffman, K. C. Future patterns of Energy Utilization September 30, 1977. Presented at the 1977 National Technical conference of the Canadian Gas Association, october 17-19, 1977, Montreal Canada.

Methodology for Comparative Evaluation of Nuclear Fuel Reprocessing Techniques for Advanced Low Proli.feration Risk Fuel: Cycles. " Miami Conference on Alternative Energy Sources, Miami, Florida, December $5-7,1977$.

Nathans, R. and Palmedo, P. Energy Plannirig and Management in Developing Countries: Thoughts Concerning a Conceptual Framework. October 11, 1977. 
BNL 23420

BNL 23508

BNL 50553

BNL 50633

BNL 50634

BNL 50635

BNL 50642

BNL 50646

BNLL 50668

BNL 50678

BNL 50679

BNL 50685
Bodin, L., Kydes, A., and Rosenfield, D. UCOST: A Micro Approach to a Transportation planning problen Submitted to: Jourmal of Urban Analysis.

Meier, P. M. A Linear Programming Approach to county Level Energy Scenario Disaggregation. Prepared for Presentation at the Joint National. ORSA/TIMS Meeting Atlanta, Georgia, November 8, 1977.

Mccoy, T., Meier, P., and Rahman, S. Issues in the Future Supply of Electricity to the Northeast. June 1976.

Carroll, T. O., Nathans, R., Palmedo, P. F. and stern, R. The Planner's Energy Workbook - A User's Manual for Explorịng. Land Use and Energy Utilization Relationships.

Carroll, T. O., Kydes, A., and Sanborn, J.' Land Use Energy Simulation Model. June 1977.

Carroll, T. O., Nathans, R. and Palmedo, P. F. Land Use and Energy Utilization Final Report.

Cherniavsky, E. A. and Goldberg, M. D. Validation and Assessment of the RESPONS Model. December 1976.

Carhart, S., Marcuse, W. and Tessmer, R. 'Energy Reserves. March 1977

Policy Analysis Division. Annulal Report for Fiscal Year 1976, December 1976.

Hoffman, K. C. Annual Highlights of the National. Center for the Analygis of Energy Systems. November 1976.

Policy Analysis Division. State Legislatures and Energy Policy in the Northeast: Energr Facility Siting and Legislative Action. Tune 1.977.

Cherniavsky, E. A., Davidoff, J., and Kydes, A. S. Multi-objective Function Analysis of ERDA Forecast-2, Year 2000 Scenario. May 1977. 
NL 50694

Anderson, R., Braun, C., Gangwer, T., Goldstein, M., Goellner, D., Lester, R., Malone, R., Selvaduray, C., Sevian, W. Waste Management and Proliferation: An Assessment of Technologies and Policies Relevent to Nuclear Power. Final Report, June 1975 - March 1977.

BNL 50696

Abilock, H., Beller, M., Cherniavsky, E. A., Hermelee, A., Juang, L. L., and Marcuse, W. Energy Modeling and Data Support for the Electric Power Research Institute. July 1977.

\section{Energy Technology}

BNL-NUREG 22411 Isaacs, H. S. The Influence of Impurity Distribution and Gas Composition on Graphite oxidation in Helium Conference: American Nuclear society 1977, winter Meeting, San Fransico, California, November 27 December 2, 1977.

BNL 23130

Milau, J., Rosso, M. J., Strickland, G. Some observations on the Effects of the Volumetric Expansion of Iron-Titanium Hydride on Vessels Built at BNL.

BNL 23145

Johnson, J.R. and Reilly, J. J.. The Use of Manganese Substituted Ferrotitanium Älloys for Energy storage (Extended Abstract) Conference: Alternative Energy Sources Symposium, Mịami Beach, Florida, December $5-7,1977$.

BNL 23161

Strickland, G. State-of-the-Art summary of the Technical Problems Involved in the storage of Hydrogen Via Metal Hydrides (Extended: Abstract).

BNT, 2..3.1.92

Lazareth, 0.. Spergel, M. Effects of Isotopic Abundance on KERMA in Naturally occurring Targets:

Chlorine. August 23, 1977.

BNT., 23207

Lu, P. W. T. , and Srinivasan, S. ElectrochemicalEllipsometric studies of Oxide Films Formed on Nickel During oxygen Evolution.

BNL 23258

Johnson, J. R. and Reilly, J. J. The Reaction of Hydrogen with TiCr2 and the Use of l'ernary Ti-CrTransition Metal Alloys for Hydrogen storage. Abstract

BNL 23297

McBreen, J. Batteries - An Overview of the stateof-the-Art. 
BNL 23352

BNL 23405

BNL 23485

BNL 23486

BNL 23487

BNL 23574

BNL 50671

BNL 50704

TID -27717
Isaacs, H. S., Russell, P. G., Srinivasan, S. and Tseung, A. C. C. Studies on Glass Composites and Doped Rutile as Interconnection Materials.

Hamilton, D., Kerwin, W., McBreen, J., McCormick, B., and Srinivasan, S. Fuel cells for Transportation.

Lu, P. W. T. and Srinivasan, S. State of Development in the Area of Water Electrolysis (Near Term).

Fishbone, I. G. Einstein's Ideas: A Course on Special Relativity for General Students.

Lu, P. W. T. and Srinivasan, S. ElectrochemicalEllipsometric Studies of Oxide Film Formed on Nickel During Oxygen Evolution.

Johnson, J. R. and Reilly, J. J. The Metal Hydride Development Program at Brookhaven National Laboratory.

Andrews, J. W., and Wilhelm, W. Low-Cost SiteAssembled Solar Collector Designs for Use with Heat Pumps. May. 1977

Auh, P. C. A Survey of Absorption Cooling Technology in Solar Applications.

FRnA Pyeparul by the nd Hoc Committee. Ari Evaluation of the Use of Hydrogen as a Supplement to Natural Gas June 1977 . 